Published in final edited form as:

Nat Prod Rep. 2018 June 20; 35(6): 514-531. doi:10.1039/c8np00011e.

\title{
Recent trends in the structural revision of natural products
}

\author{
Bhuwan Khatri Chhetria,c, $\dagger$, Serge Lavoie ${ }^{b, c, \dagger}$, Anne Marie Sweeney-Jones ${ }^{a, c, \dagger}$, and Julia \\ Kubanek $\mathbf{k}^{\mathrm{a}, \mathrm{b}, \mathrm{c}, \mathrm{d}}$ \\ aSchool of Chemistry and Biochemistry, Georgia Institute of Technology, Atlanta, GA, 30332, USA \\ bSchool of Biological Sciences, Georgia Institute of Technology, Atlanta, GA, 30332, USA \\ 'Aquatic Chemical Ecology Center, Georgia Institute of Technology, Atlanta, GA, 30332, USA \\ dParker H. Petit Institute for Bioengineering and Bioscience, Georgia Institute of Technology
}

\begin{abstract}
This article reviews recent reports on the structural revision of natural products. Through a critical assessment of the original and revised published structures, the article addresses why each structure was targeted for revision, discusses the techniques and key discrepancies that led to the proposal of the revised structure, and offers measures that may have been taken during the original structure determination to prevent error. With the revised structures in hand, weaknesses of original proposals are assessed, providing a better understanding on the logic behind structure determination.
\end{abstract}

\section{Table of content}

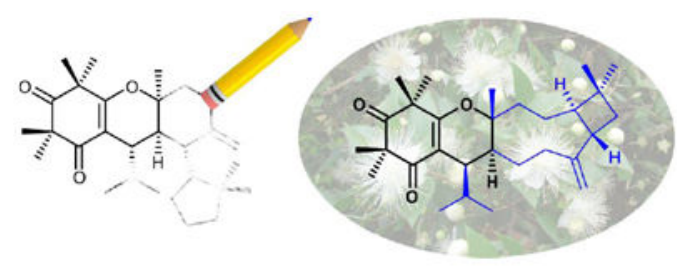

Case study-based review on misassigned structures and measures to avoid erroneous assignments during structure determination

\section{Introduction}

Human medicine has relied on bioactive natural products and their derivatives for the treatment of a wide variety of diseases. In fact, a substantial proportion of all FDA approved drugs are natural products or their derivatives. ${ }^{1}$ The biological activities of these molecules are governed by their three-dimensional structures and the functional groups present. ${ }^{2,3}$ Failure to establish the correct structure can dramatically alter the course of a drug

Correspondence to: Julia Kubanek.

$\dagger$ These authors contributed equally

Conflicts of interest

There are no conflicts to declare. 
development program, as exemplified by the TIC10 case. This drug candidate, identified from a free NCI database, was found to be active against a plethora of cancer cell lines. ${ }^{4}$ Scientists uninvolved in the original compound discovery demonstrated that the structure from the NCI database used for an earlier TIC10 patent was incorrect and they subsequently filed their own patent with the correct structure. This led to a legal disagreement that is still ongoing. ${ }^{5}$ Hence, knowledge of the correct structure of a natural product, especially if it is a starting point for the development of a drug, is crucial.

In the past, structure determination was an arduous process occupying years of effort. Studies to identify molecular structures relied on degradation, derivatization, and characteristic reactivities of the functional groups, all based on synthetic chemistry. ${ }^{6} \mathrm{X}$-ray crystallography, available since the 1920 's, ${ }^{7,8}$ has been considered the gold standard for structure elucidation. However, it is limited to samples with sufficient material that can be crystallized, is not always suitable for establishing absolute configuration, and does not always lead to accurate prediction of bonding relationships as demonstrated by the revision of diazonamide B. ${ }^{9}$ In the late 1960's, NMR spectroscopy started to establish itself as an indispensable tool for structure determination prompting a renewed era of drug discovery. ${ }^{10}$ In recent years, computational prediction of NMR and other spectroscopic properties has made spectral interpretation more accurate. ${ }^{11,12}$ According to Koji Nakanishi (1991): "Until the mid-1960s, structure determination was an art that could be likened to solving a complicated detective case, but with the spectacular advancement in spectroscopy it has become less inspiring, and since the mid-1980s, in most cases, structure determination has become rather routine." 13 However, it is important to note that although structure determination benefits from the vast array of spectroscopic techniques now available, there are still challenges inherent to identifying novel and complex natural products that enrich the elucidation process. Use of spectroscopic techniques to identify a molecule is an inverse problem, meaning that one uses observations about acquired data to discard all solutions but the most logical one. ${ }^{14}$ Thus, individual bias can potentially result in a proposed structure that is a mere figment in the eyes of the beholder rather than a product of critically testing all possible hypotheses.

Previous reviews have evaluated important cases of erroneous structures and their revisions, bringing awareness to the surprisingly large number of structural misassignments reported in the literature. Nicolaou and Maier emphasized the value of total synthesis in confirming the structure of natural products, 6,15 whereas Lawrence highlighted the contribution of biosynthetic rationalization of natural products to structure determination. ${ }^{16}$ A tabulated review presented by McPhail covered marine natural product revisions from 2005-2010. ${ }^{17}$ In the current publication, we review 23 unique structural revision cases reported from 2012 to 2017, each showcasing different approaches including computational chemistry, NMR spectroscopic methods, empirical rules, techniques in X-ray crystallography, and biosynthetic studies that revealed and resolved structural errors. 


\section{Structural revision based on computational prediction of NMR spectroscopic data}

The field of natural products has advanced considerably with the development of technology that has resulted in the ability to compare experimentally derived NMR spectroscopic data with predictions generated by computational chemistry. ${ }^{18-20}$ These computational methods have become increasingly accessible with the development of user-friendly software and increased computing speed. In addition to aiding the structure elucidation of new natural products, computational methods have found great utility in helping to uncover and ultimately revise errors in previously reported compounds. The case studies included in this section exemplify the efficacy of computational prediction towards correcting errors in molecular structures of natural products.

\subsection{Aldingenins A-D}

The red algal genus Laurencia has been the source of many isoprenoid natural products, including the chamigrene sesquiterpene (-)-elatol, ${ }^{21}$ the halogenated sesquiterpenes rhodolaureol and rhodolauradiol, ${ }^{22}$ and the brominated bisabolene derivatives aldingenin AD (1-4). ${ }^{23,} 24$ The molecular masses of 1-4 were determined using HREIMS and the structures (1a-4a) were based on analysis of 1D and 2D NMR spectra. ${ }^{25}$ Comparison of NMR spectroscopic data of synthesized aldingenins $B$ and $C$ with natural isolates did not agree with the proposed structures $2 \mathbf{a}$ and $\mathbf{3 a} .{ }^{25,}{ }^{26}$ Studies on aldingenin C (3) and D (4) using computer-assisted chemical structure elucidator (CASE), ${ }^{27}$ revealed that they were in fact the known compounds caespitol $(\mathbf{3 b})$ and $5 S$-acetoxy-caespitol $(\mathbf{4 b}) .{ }^{26}$ Based on this realization, Kutateladze and coworkers used a newly developed strategy to calculate spinspin coupling constants named relativistic force field (rff), using an optimized basis set (DU8c) and scaled Fermi contacts to identify the correct structures for aldingenins A (1b) and B (2b). ${ }^{28}$ Not surprisingly, the newly proposed structures bear chlorine atoms, as do caespitol (3b) and $5 S$-acetoxycaespitol (4b). It is unclear how the MS signatures of natural products with two bromine and one chlorine atoms could be confused with those possessing only one bromine. One possible explanation is that electron impact ionization led to weak molecular ion peaks for these non-aromatic halogenated compounds. ${ }^{29}$
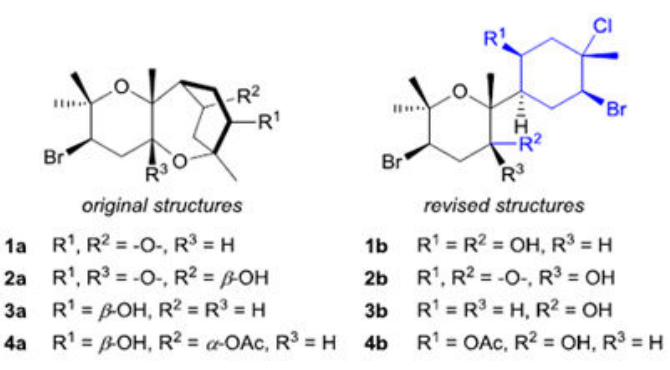

\subsection{Decurrensides A-E}

After decurrensides A-E (5-9) were isolated from the Chinese herb Solidago decurrens, ${ }^{30}$ the proposed structure 8a was synthesized; however, the NMR spectroscopic data did not match the natural product. ${ }^{31}$ This discrepancy led to the revelation that the depicted 
structures 5a-9a did not match the compound names. More specifically, the paper proposed 5-9 to be 2,6-hemiacetal-3-deoxy-D-altro-2-octulsonic acids (5a-9a) but named them 3deoxy-D-manno-2-octulosonic acids. Further studies based on computation of $\delta_{\mathrm{C}}$ and the proton spin-spin coupling constants determined that both the original name and depiction of 5-9 were incorrect and instead should be revised to 2,6-anhydro-3-deoxy-D-manno-2octulopyranosonates (5b-9b). ${ }^{32}$ DFT-based computation of $\delta_{\mathrm{C}}$ for $\mathbf{8 a}$ using the gaugeincluding atomic orbital (GIAO) method showed poor correlation with the experimental values, including a deviation of more than $10 \mathrm{ppm}$ for the hemiacetal carbon. In the original proposal 5a-9a, a spin system involving four consecutive $5 \mathrm{~Hz}$ spin-spin coupling constants was reported between $\mathrm{H}_{2}-3 / \mathrm{H}-4 / \mathrm{H}-5 / \mathrm{H}-6 / \mathrm{H}-7$. Relativistic force field and $D U 8 c$ based coupling constant calculations on the proposed structure predicted $J_{\mathrm{H}-6, \mathrm{H}-7}$ to be $0.2 \mathrm{~Hz}$, which was drastically smaller than the reported value of $5 \mathrm{~Hz}$. When computational predictions were made for $a$ - and $\beta$-2,5-hemiacetals of the methyl ester of 8- $O$-benzoyl-3deoxy-D-altro-2-octulosonic acid, both 2,5- and 2,6-hemiacetals of 3-deoxy-D-manno-2octulofuranosonic acid, and the two ketal forms of 3-deoxy-D-manno-2-octulofuranosonic acid, none of the generated values for these structures matched the experimentally acquired spectral data for $\mathbf{8}$. The core structure 2,6-anhydro-3-deoxy-2-octulopyranosonic acid was found to closely match experimental spectral data of $\mathbf{8}$ through comparison of computationally derived $\delta_{\mathrm{C}}$ and $r f f$-calculated $J$-coupling values. In support of the revision, 5b-9b contain a common spin system with four consecutive protons all having dihedral angles of $40-50^{\circ}$ between vicinal neighbors resulting in the expected sequential $5 \mathrm{~Hz}$ coupling constants. Ultimately, rff based calculations of nuclear spin-spin coupling constants and prediction of $\delta_{\mathrm{C}}$ led to the conclusion that structures 5-9 consist of a 2,6-anhydro-3deoxy-D-manno-2-octulopyranosonate core with different substitution in the C-8- $O$-acyl and C-1 ester.

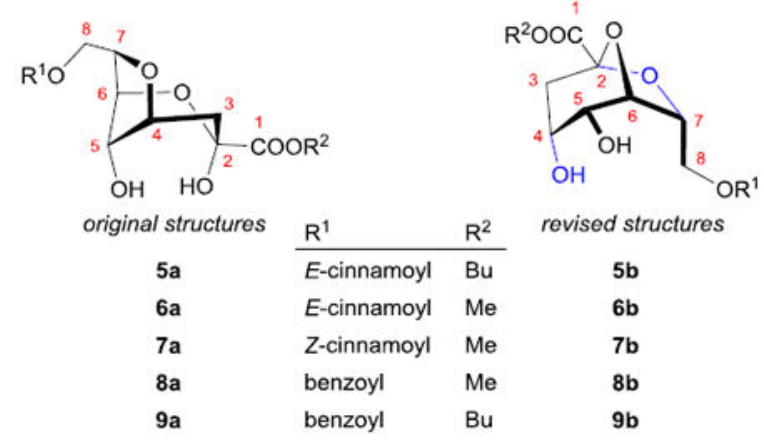

\subsection{Tristichone}

Tristichone $\mathrm{C}(\mathbf{1 0})$ is a chamigrane-type sesquiterpene obtained from the marine red alga Laurencia tristicha. ${ }^{33}$ Its structure (10a) was elucidated using HRMS and NMR spectroscopic analysis, but no experimental evidence was provided to support the relative positions of the bromine and chlorine atoms. Recently, Kutateladze et al. developed a quadratic scaling correction to be used in conjunction with their $r f f$ method to take into account the effect of spin-orbit contribution on predicted $\delta_{\mathrm{C}}{ }^{34}$ The correction parameters were obtained from an experimental training set of more than $400 \delta_{\mathrm{C}}$ for carbon attached to 
$\mathrm{S}, \mathrm{Cl}, \mathrm{Br}$ or I. Among the 119 molecules chosen in this study, the structures of 16 were subsequently revised. Misassignments ranged from incorrect stereochemistry to incorrect carbon skeletons. The predicted chemical shift for the chlorine-bearing carbon atom of 10a deviated by $6.6 \mathrm{ppm}$ from the experimental value, but the constitutional isomer 10b resulted in a much better fit. Interestingly, this computational prediction is in perfect agreement with a previous empirical study in which the $\delta_{\mathrm{C}}$ for a series of polyhalogenated compounds similar to $10 \mathrm{a}$ and $\mathbf{1 0 b}$ were reported. ${ }^{35}$

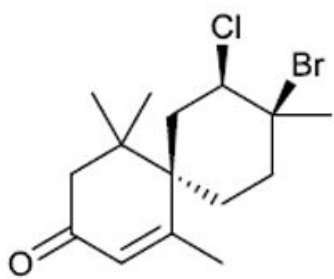

$10 \mathrm{a}$

original structure<smiles>CC1=CC(=O)CC(C)(C)[C@]12CC[C@@](C)(Cl)[C@@H](Br)C2</smiles>

$10 \mathrm{~b}$

revised structure

\subsection{Glabramycins B and C}

Antibiotic glabramycins B (11) and C (12) were isolated from Neosartorya glabra, a fungus obtained from soil samples. ${ }^{36}$ In the original proposal for glabramycin B (11a), an anti relationship between C-10, C-11, and C-15 was proposed based on the triplet resonance of 9.6 Hz observed for $\mathrm{H}-10$ whereas the configuration at $\mathrm{C}-20$ was not determined. The decalactone polyketide structure of glabramycins B (11) and C (12) are closely related to the natural product dictyosphaeric acid, where C-11 exhibits a syn configuration relative to $\mathrm{C}-10 .{ }^{37}$ Prompted by this difference in the configuration at $\mathrm{C}-11$, the proposed structures of glabramycins and their possible diastereomers at position $\mathrm{C}-11$ and $\mathrm{C}-20$ were subjected to $\delta_{\mathrm{C}}$ DFT calculation. Coupling constants between $\mathrm{H}-10$ and $\mathrm{H}-11$ and between $\mathrm{H}-11$ and H-12 were also predicted computationally for all the diastereomers. ${ }^{38}$ Calculated $\delta_{\mathrm{C}}$ and $J$ values favored $\mathbf{1 1 b}$ and $\mathbf{1 2 b}$ as the correct structures of glabramycins. This result was recently confirmed through total synthesis of $\mathbf{1 1 b} .{ }^{39}, 40$ The original proposal lacked a key literature precedent: the structure determination of dictyosphaeric acid, which has the same decalactone moiety as glabramycins, utilized a $J$ based configuration analysis to explain the large coupling constant observed for the eclipsed configuration between $\mathrm{H}-10$ and $\mathrm{H}-11 .{ }^{37,} 41$

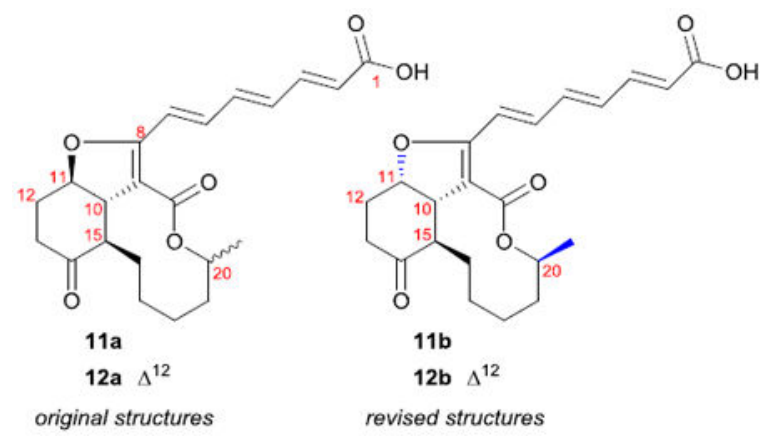




\subsection{Synargentolide A}

Syncolostemon argenteus, a South African plant of the mint family Lamiaceae, produces the 5,6-dihydro-a-pyrone synargentolide A (13). ${ }^{42}$ To determine its absolute configuration, the compound was fully hydrolyzed and transformed into 5- and 6-membered acetonides. First, the 5-membered ring acetonide tethering alcohols at positions 4' and 5' was used to deduce the relative configurations of these positions, as well as the configuration of the free alcohol at position 6' using derivatization of its a-methoxy-a-trifluoromethylphenylacetate ester. To relate the configuration of the alcohol at C-6' with the two other stereocenters, $\delta_{\mathrm{C}}$ of the two methyl groups on the 6-membered acetonide between alcohols 4' and 6' were compared with each other (Fig. 1A). Since different chemical shifts were obtained for the methyls of the acetonide, the authors concluded that the acetonide adopted a chair conformation which translates to a syn configuration of the corresponding 1,3-diol and the overall structure 13a. Yet when 13a was synthesized, ${ }^{43}$ the NMR spectroscopic data did not match those originally reported. In a subsequent study, the $4^{\prime} R, 5^{\prime} R, 6^{\prime} R$ isomer was synthesized and proposed as the absolute configuration of $\mathbf{1 3}$ based on visual comparison of ${ }^{1} \mathrm{H}$ NMR spectral features. ${ }^{44}$ However, extraction of chemical shifts and $J$ coupling constants by non-linear fitting of the spectra obtained from the natural product and the synthetic diastereoisomer highlighted slight differences disproving the revision. ${ }^{45}$ Further predictive calculation of the coupling constants by DFT computation of four possible diastereoisomers suggested the configuration to be $\mathbf{1 3 b}$. The simulation took advantage of the spin-spin option in the program Gaussian $09^{46}$ which calculates the scalar coupling constant as a summation of Fermi contact, spindipolar, paramagnetic spin-orbit, and diamagnetic spin-orbit. ${ }^{47}$ The reason for the erroneous stereochemical assessment in the original proposal is uncertain. The acetonide strategy has been extensively studied from the conformational point of view ${ }^{48}$ and suffers no exception when the acetonide is substituted at C-5', as in this case. ${ }^{49}$ Also, it was shown that substituents at C-4' or C-6' exhibiting weak steric hindrance, like nitrile or alkyne derivatives, may produce an anti acetonide. This could mislead configurational assignment since anti acetonides, which normally adopt a twist-boat conformation, can flip to a chair conformation (Fig. 1B). ${ }^{50}$ However, the methyl group of $\mathbf{1 3}$ was not shown to be small enough for this to happen. A possible alternative hypothesis is that epimerization was triggered by the harsh hydrolysis conditions $\left(0.5 \mathrm{M} \mathrm{NaOH}\right.$ in $\mathrm{MeOH} / \mathrm{H}_{2} \mathrm{O}$ for 2.5 days, followed by acidification and heating up to $100{ }^{\circ} \mathrm{C}$ for $2 \mathrm{~min}$ ) or during acetonide formation in acetone with amberlyst $15 .{ }^{42}$

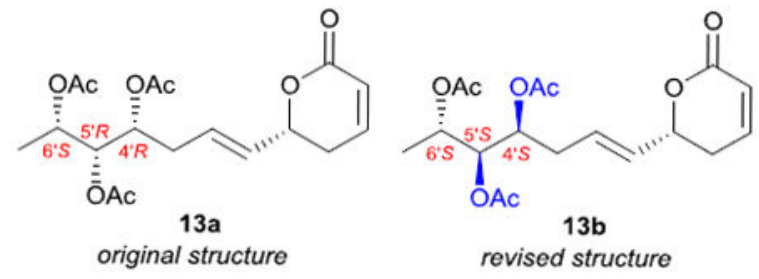

\subsection{Cordycepol A}

Cordycepol A (14), along with analogues B and C, were isolated from Cordyceps ophioglossoides, a fungus that colonizes other fungal species. ${ }^{51}$ NOESY cross-peaks between $\mathrm{H}_{3}-14 / \mathrm{H}-1, \mathrm{H}_{3}-15 / \mathrm{H}-1$ and $\mathrm{H}_{3}-14 / \mathrm{H}-9$ supported the relative configuration of the 
spiro[4.5]decane ring system of $\mathbf{1 4 a}$ (Fig. 2). However, the structures of $\mathbf{1 4}$ and its analogues were recently revised. ${ }^{52}$ The calculated $J_{\mathrm{H}-1, \mathrm{H}-2 \mathrm{~b}}$ and $J_{\mathrm{H}-1, \mathrm{H}-2 \mathrm{a}}$ as well as chemical shifts of C-1, C-2, C-6, C-7, C-10, and C-12 derived using the rfflDU8c parametric method for 14a significantly diverged from the experimental NMR spectroscopic data. In contrast, the calculated parameters of the revised structure 14b very closely match the experimental values. The original proposal contains a NOESY correlation between $\mathrm{H}_{3}-15$ and $\mathrm{H}-1^{51}$, which should be at least $6.4 \AA$ apart based on computational predictions. It is possible that $\mathrm{H}-1$ was wrongly assigned since several ${ }^{1} \mathrm{H}$ NMR signals were reported in the same range $\left(\delta_{\mathrm{H}} 1.00-1.50\right)$, but in the absence of public access to free induction decay (FID) files as proposed by Pauli, ${ }^{53}$ this cannot be confirmed.

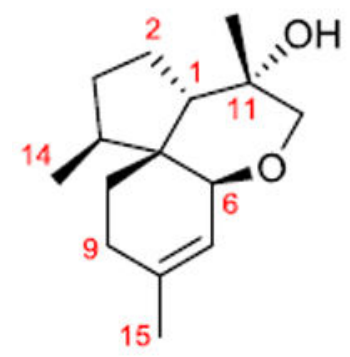

$14 a$ original structure

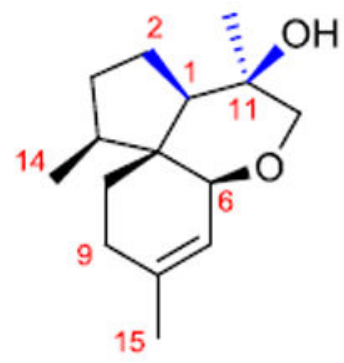

$14 \mathrm{~b}$

revised structure

\subsection{Meridane}

A complex mixture of $7 \beta, 9 a$-longipinene diesters extracted from the leaves and stem of Stevia lucida were subjected to hydrolysis, oxidation, acid-catalyzed dehydration, and rearrangement. ${ }^{54}$ This yielded meridane, proposed as 15a based on NMR spectroscopic evidence and a rational reaction mechanism of formation. Shortly thereafter, the structure 15a was disproved based on comparison of experimental and computed $\delta_{\mathrm{C}}$ using (GIAO mPW1PW91/6-311+G(d,p)). ${ }^{55}$ Close examination of the reaction conditions and other possible rearrangement pathways led to the alternative structure $\mathbf{1 5 b}$, supported by computed $\delta_{\mathrm{H}}, \delta_{\mathrm{C}}, J_{\mathrm{H}-\mathrm{H}}$ and $J_{\mathrm{C}-\mathrm{H}}$. It is difficult to envision what could have been done to avoid this misassignment, since all HMBC correlations equally support the original and the revised structure.

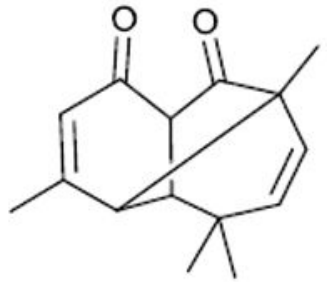

$15 a$ original structure<smiles>CC1=CC(=O)C2C3C(=O)C2C(C)(C=CC3(C)C)C1</smiles>

15b

revised structure 


\subsection{Brassicicenes}

The plant pathogen Alternaria brassicicola infects most Brassica species and produces brassiciccene diterpenes 16-23 that are phytotoxic. ${ }^{56-58}$ These molecules belong to the fusicoccane terpenoid family which has been extensively studied for their interesting biological activities. ${ }^{59-63}$ Initial computational studies predicted chemical shifts deviating 10-11 ppm from observed data for C-7 of 16a and C-10, C-13 and C-18 of 22a, disfavoring the proposed structures. ${ }^{56,64}$ Also, the original proposal placed $\mathrm{H}-17$ and $\mathrm{H}-186.8 \AA$ apart, which did not meet expectations for an observed NOE correlation (22a, Fig. 3). Recently, 22 was reisolated and revised to $\mathbf{2 2 b}$ by pairing quantum-chemical predictions with extensive NMR spectroscopic analysis, resulting in stronger agreement between calculated and experimental $\delta_{\mathrm{C}}$ along with favorable NOE distances supporting correlations between H-18 and H-17 (Fig. 3). ${ }^{64}$ The structure was further validated using X-ray crystallography and electronic circular dichroism spectroscopy (ECD) for absolute stereochemistry. Subsequently, structures of other brassicicene diterpenes 17-21 and 23 were also revised based on $\delta_{\mathrm{C}}$ calculations. ${ }^{64}$ In the original studies, ${ }^{56,57}$ important HMBC correlations to support the structures were missing. For example, an isolated spin system of brassicicene $\mathrm{G}$ (19), composed of the methyl $\mathrm{H}_{3}-18$ and the methine $\mathrm{H}-12$, was proposed based on an HMBC correlation of H-12 with C-1, C-10, C-11 and C-13, but the more important HMBC correlations from $\mathrm{H}_{3}-18$ were not reported.

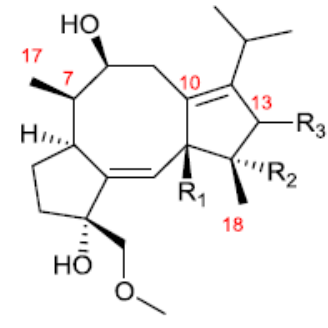

original structures

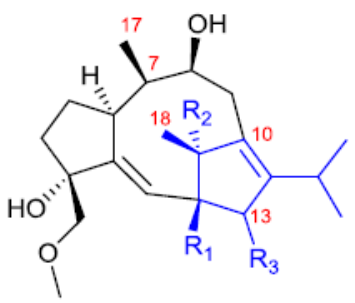

revised structures

\begin{tabular}{lllll} 
& $R^{1}$ & $R^{2}$ & $R^{3}$ & \\
\cline { 2 - 3 } $16 a$ & $H$ & $H$ & $=O$ & $16 b$ \\
$17 a$ & $O H$ & OAc & $=O$ & $17 b$ \\
$18 a$ & $H$ & $O H$ & $=O$ & $18 b$ \\
$19 a$ & $O H$ & $H$ & $=O$ & $19 b$ \\
$20 a$ & $H$ & $H$ & $\cdots \cdot \cdots H$ & $20 b$ \\
$21 a$ & $H$ & $O O H$ & $=O$ & $21 b$
\end{tabular}

\subsection{Type C Polycyclic Polyprenylated Acylphloroglucinols}

Polycyclic polyprenylated acylphloroglucinols (PPAPs) are a class of compounds featuring a highly oxygenated bicyclo[3.3.1]nonane substituted by prenyl side chains. ${ }^{65}$ These compounds are found exclusively in plants from the Clusiaceae family, which includes StJohn's wort (Hypericum perforatum), well known for diverse medicinal properties. ${ }^{66}$ There are three categories of PPAPs, types A, B, and C, distinguished by the position of the acyl moiety relative to the quaternary center of the prenyl side chain (Fig. 4) ${ }^{65} \mathrm{~A}$ series of the rare type C PPAPs were isolated from the seeds of Garcinia subelliptica with structures 24a-26a elucidated by conventional MS and multidimensional NMR spectroscopy. ${ }^{67}$ 
However, no experimental evidence was provided to support whether the prenyl side chain was located at C-5 (type A) or C-1 (type C). In a recent examination of Hypericum cohaerens, the structures of 24-26 were revisited. ${ }^{68}$ Three-dimensional models of both type C (24a) and type A (24b) were subjected to a molecular mechanic conformational search followed by DFT geometrical optimization, frequencies and thermochemical computation, and $\delta_{\mathrm{C}}$ prediction, all at the mPW1PW91/6-31G(d,p) level of theory. The predicted spectroscopic data for $\mathbf{2 4 b}$ were in closer agreement with experimental values, especially for positions 1 and 6, which were the most impacted by the acyl group. The same rationale was used to revise co-isolated PPAPs to $\mathbf{2 5 b} \mathbf{- 2 6 \mathbf { b }} .{ }^{68}$ It is worth noting that while the 3D structures for $\mathbf{2 4 a}$ and $\mathbf{2 4 b}$ provided in the supplemental information of the revision were correct, the structures of $\mathbf{2 4 a}$ and $\mathbf{2 4 b}$ portrayed in the main manuscript were depicted incorrectly with an $a-\mathrm{H}$ at $\mathrm{R}^{3}$ rather than a $\beta-\mathrm{H} .{ }^{68}$ The structures included in the current review are based on the correctly portrayed $3 \mathrm{D}$ structures.

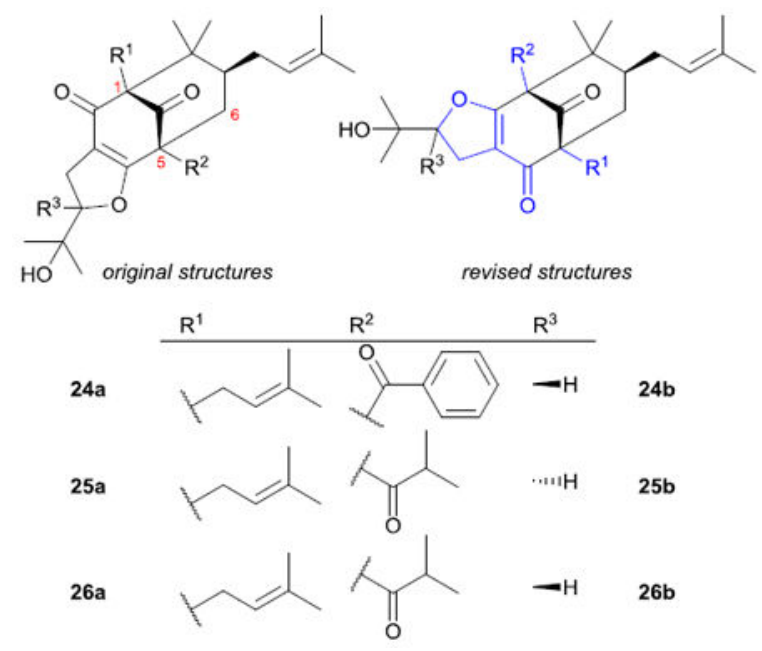

\section{Structural revision based on calculation of chiroptical properties}

A major challenge often encountered by chemists attempting to elucidate structures of natural products is determination of relative and absolute configuration. ${ }^{69}$ The chiroptical properties of these chemicals are often the only parameters available to distinguish some types of isomers. Advances in computational tools have elevated the empirical interpretation of chiroptical properties to a true predictive methodology aiding in assignment of configuration. ${ }^{70}$ These new methods have contributed to corrections of erroneous structures, as demonstrated in the following cases.

\subsection{Brevianamides}

Diketopiperazine alkaloids are a rich class of cyclic dipeptide molecules exhibiting a range of biological properties. ${ }^{71-74}$ Brevianamide $\mathrm{M}(\mathbf{2 7})$ and its oxidation product 28 were isolated from Aspergillus versicolor along with a related diketopiperazine dimer and oxepincontaining alkaloids. ${ }^{75}$ The relative configuration of the two stereocenters in $\mathbf{2 7}$ was determined by X-ray crystallography to be $(2 R, 13 R)$ or $(2 S, 13 S)$. Hydrolysis of the natural products in aqueous solution gave L-phenylalanine suggesting an $S$-configuration at position 
13 , which led to the proposal of a $(2 S, 13 S)$ configuration for $27 \mathbf{a}$. However, in contrast to the positive optical rotation calculated for the proposed configuration 27a using four different DFT quantum chemical models, the molecule showed an experimental optical rotation of $-147.7^{\circ}$, suggesting a $(2 R, 13 R)$ configuration. ${ }^{76}$ After careful analysis of this discrepancy, the hydrolysis process was questioned since it could cause epimerization at C-13 of $27 \mathbf{b}$ to form the low energy diastereomer $27 \mathbf{c}$ that could hydrolyze to give Lphenylalanine (Fig. 5). As expected, DFT studies predicted the epimer $27 \mathbf{c}$ to be energetically more stable than $\mathbf{2 7 b}$ with a predicted conversion rate of more than $92 \%$. Since $\mathbf{2 8}$ was isolated using the same procedure as $\mathbf{2 7}$, it was proposed to share the same absolute configuration. The reassignments were confirmed by agreement between experimental data and DFT computed optical rotation, predicted VCD spectra, and the theoretical prediction of positive and negative cotton effects for ECD spectra. ${ }^{76}$

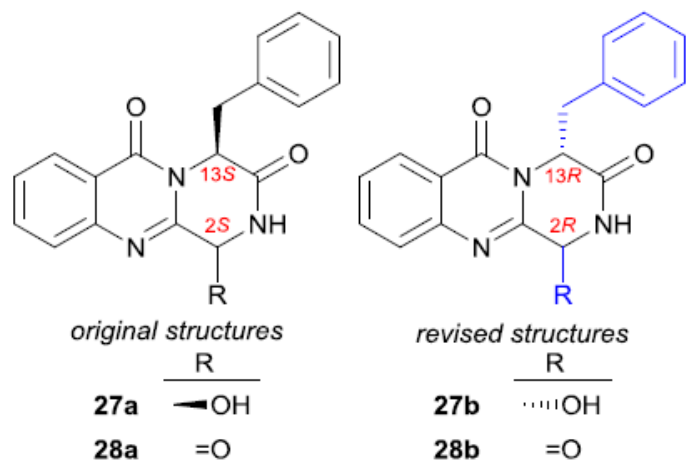

\subsection{Castalagin and vescalagin}

Castalagin (29) and vescalagin (30) are epimeric ellagitannins exhibiting antioxidant, antiviral, and inhibitory activity against DNA topoisomerase II. ${ }^{77,78}$ They were initially isolated from the wood of chestnut (Castanea sativa) and oak (Quercus sesseliflora) but their exact atropisomerism configuration could not be determined at that time. ${ }^{79-81}$ The configuration for the nonahydroxytriphenoyl group was proposed to be $(S, S)$ based on a comparison of the circular dichroism spectrum with the one obtained for a model compound of known configuration. ${ }^{82} \mathrm{In}$ a follow-up molecular mechanics study, it was proposed that an $(S, R)$ configuration at the nonahydroxytriphenoyl group would be more stable. ${ }^{83}$ The discrepancy in proposed configurations was resolved by predicting the ECD spectra of hydrolyzed analogues castalin (31) and vescalin (32) using TDDFT calculation. ${ }^{84}$ The hydrolysis was necessary since strong Cotton effects from the $(S)$-hexahydroxydiphenoyl ester overlapped with the small Cotton effects of the triphenoyl group. The experimental ECD spectra obtained for $\mathbf{3 1}$ and $\mathbf{3 2}$ were in agreement with the predicted spectra of the $(S, R)$ configuration. This led the authors to conclude that castalagin and vescalagin could be revised to $29 \mathrm{~b}$ and $30 \mathrm{~b}$, respectively. To confirm the ECD spectroscopy results, DFT prediction of $\delta_{\mathrm{H}}$ and $\delta_{\mathrm{C}}$ were performed ${ }^{84}$ and found to be in good agreement with experimental values for $\mathbf{2 9}$ and $\mathbf{3 0}{ }^{85}$ 


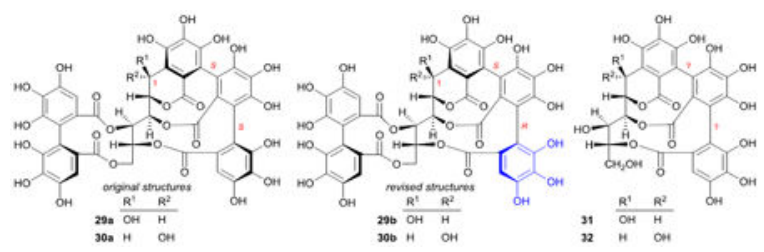

\subsection{Nudicaulin}

The flower petals of Papaver nudicaule owe their yellow color to a group of glycosides called nudicaulins. ${ }^{86}$ After extensive NMR spectroscopic analysis, nudicaulin I was suggested to possess an unprecedented $10 H-1,10$-ethenochromeno[2,3-b]indole moiety (33a). The downfield chemical shift of C-2 led the authors to propose that this position was attached to one of the oxygens of ring A, leading to the asymmetry needed to explain the two distinct ${ }^{1} \mathrm{H}$ NMR signals of $\mathrm{H}-5$ and H-7 within ring A. Similarly, the relatively upfield chemical shift of C-19 was interpreted as an indication for a bond between C-19 and the indole nitrogen. However, if 33a was stable enough to be isolated, it would be expected to experience severe strain at C-2 and C- 11 which would limit the aromaticity to isolated phenyl rings rendering the molecule colorless. This prompted the revision of 33a to 33b using NMR spectroscopic data, chemical derivatization, and comparison of experimental and predicted chiroptical properties. ${ }^{87}$ The evidence included HMBC correlations from H-3 and H-18 to N-1 and ROESY correlations between H-2'/6' and H-15. The ECD spectrum of 33b was predicted with TDDFT using CAM-B3LYP functional and conductor-like polarizable continuum model (CPCM) for solvent effects of methanol. However, prediction at this level of theory was unsatisfactory and the size of the molecule precluded the use of a higher level of theory. Simplification of the molecule to a partially hydrolyzed derivative with one glucose unit at C-11 was evaluated but this prediction was also unsuccessful. Interestingly, modeling a hypothetical chemically unstable form of $\mathbf{3 3 b}$ with a hydroxyl in place of the sugar accurately predicted the experimental spectrum. While this advanced demonstration is an example of how complex a structural elucidation with quantumchemical computation can be, the authors missed a simpler solution: since the relative stereochemistry between the aglycon and the sugar moieties was determined by semiquantitative ROESY, the absolute configuration of $\mathbf{3 3 b}$ could have been deduced from the hydrolyzed glucose unit.

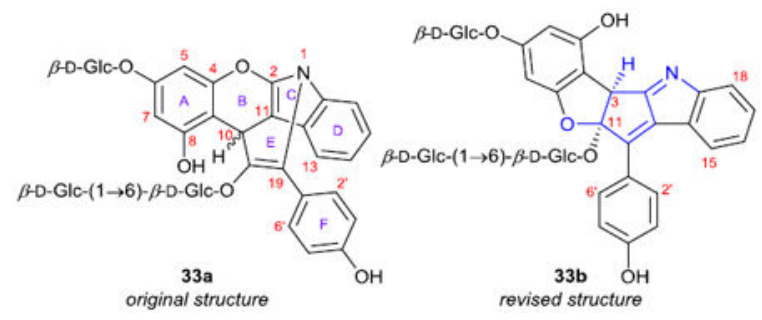

\subsection{Plakinidone}

Sponges belonging to the genus Plakortis are well known to produce molecules having cyclic five- or six- membered endoperoxide rings. ${ }^{88-91}$ Plakinidone (34), isolated from Plakortis angulospiculatus, was proposed to have a $p$-hydroxyphenyl and a six membered 
perlactone ring flanking the two ends of a ten-carbon alkyl chain (34a). ${ }^{92}$ Attempts to synthesize an analogue having the same perlactone moiety were unsuccessful which brought into question the validity of $\mathbf{3 4 a} .{ }^{93}$ Careful NMR spectroscopic analysis resulted in the

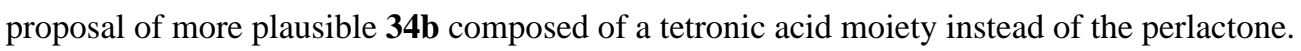
This compound and the $11 R, 17 S$ stereoisomer $\mathbf{3 4} \mathbf{c}$ were synthesized and their optical rotations were compared to the value for the isolated compound, leading to the conclusion that the correct configuration was $11 S, 17 S(\mathbf{3 4 b}) \cdot{ }^{93}$ A subsequent study challenged this finding due to the unstable nature of $\mathbf{3 4}$ and proceeded to conduct a thorough study of the chiroptical properties of re-isolated $34 .^{94}$ The $S$ configuration at C-11 was unambiguously determined by comparing the optical rotation values of the degradation product 35 and the corresponding synthetic compound 36, obtained from a 6-step sequence starting from $(S)$ citronellol. The other chiral center was determined as $17 R$ from comparison of experimental VCD and ECD spectra with those predicted from quantum chemical computation leading to the revised structure $34 d$. The difference in molecular masses of the originally proposed 34a and revised 34d was attributed to air oxidation of $\mathbf{3 4}$ which resulted in a molecular ion peak at $\mathrm{m} / \mathrm{z} 374$ for $\mathbf{3 4 d}$ instead of $\mathrm{m} / \mathrm{z} 390$ for $\mathbf{3 4 a} .^{93}$
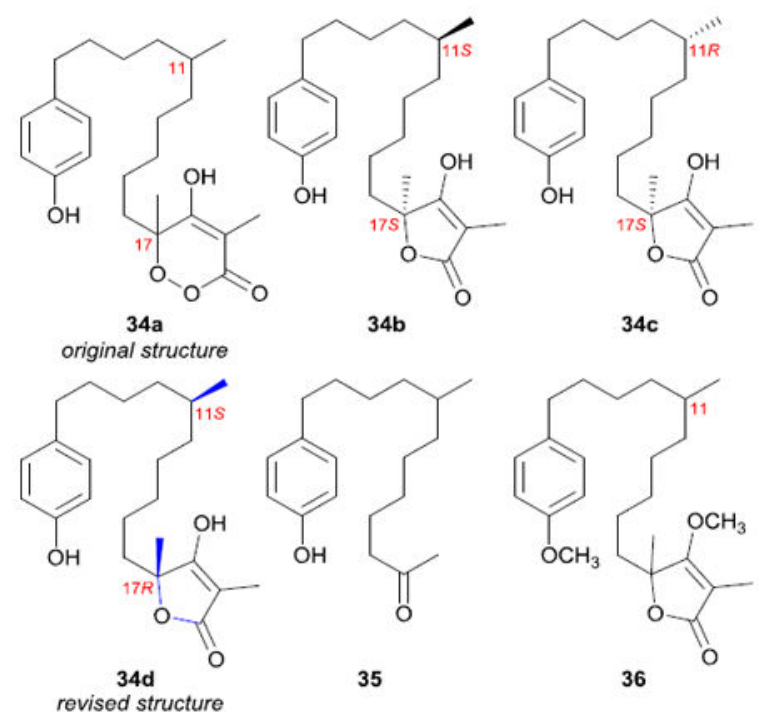

\section{Structural revision based on the crystalline sponge method and X-ray crystallography}

$\mathrm{X}$-ray crystallography is a powerful tool for structure determination; however, it requires high quality diffracting crystals in sufficient quantity. ${ }^{48,95}$ An alternative that has recently been proposed, the crystalline sponge method, utilizes a porous metal framework composed of tris(4-pyridyl)1,3,5-triazine and a metal salt to hold the target molecule of interest for crystallographic analysis, eliminating the need to obtain crystals. ${ }^{96}$ Both methods have found use in structural revision studies, as demonstrated in the subsequent case studies. 


\subsection{Cycloelatanene A-B}

Cycloelatanene $\mathrm{A}$ and $\mathrm{B}$, two $\mathrm{C}_{16}$ chamigrenes, were isolated from the Australian marine alga Laurencia elata. ${ }^{97}$ A preliminary chemical profiling using HPLC-NMR spectroscopy resulted in the isolation of the two C-4 epimeric cycloelatanenes, described as A (37a) and B (37b). Their structures were proposed from NMR spectroscopic analysis with the relative configuration established by selective 1D NOE irradiations. In a recent study, the structures were revisited using the crystalline sponge method, ${ }^{98}$ which is suitable for rigid, nonpolar molecules that are smaller than the cross-sectional area of pores of the host complex. ${ }^{99} \mathrm{X}$ ray diffraction analysis of the molecules trapped inside the ordered cavities of the crystalline sponge $\left.\left[\left(\mathrm{ZnI}_{2}\right)_{3}(\mathrm{tpt})_{2} \text { (cyclohexane) }\right)_{\mathrm{x}}\right](\mathrm{tpt}=2,4,6$-tris-(4-pyridyl)- 1,3,5-triazine) confirmed a rigid tricyclic framework for the cycloelatanenes and ultimately structure 37a was revised to $37 \mathbf{b}$ and $\mathbf{3 7} \mathbf{b}$ was revised to $37 \mathbf{a}$. A close evaluation of the reacquired 1D NOE spectroscopic data showed key correlations between $\mathrm{H}-10$ and $\mathrm{H}_{3}-13$ for $\mathbf{3 7 b}$ and between H-10 and H-4 for 37a, further supporting the revision (Fig. 6).
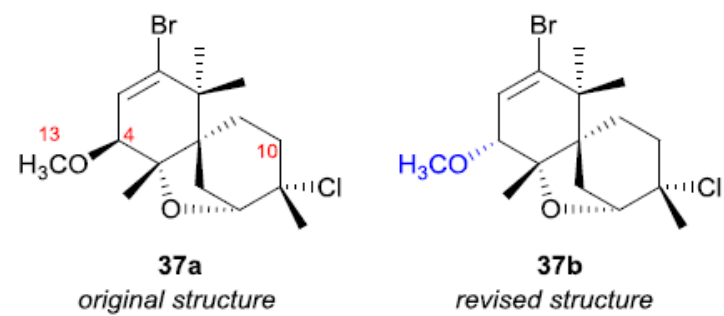

\subsection{Myrtucommulone $\mathrm{K}$}

Myrtus communis L, a Mediterranean evergreen shrub, has been traditionally used as an antiseptic, disinfectant, and hypoglycemic agent. ${ }^{100} \mathrm{~A}$ variety of bioactive compounds have been isolated from $M$. communis including the cytotoxic phloroglucinol derivative myrtucommulone K (38). ${ }^{101}$ Structure 38a was derived through MS and NMR spectroscopy, relying on two critical HMBC correlations from H-10 to C-9 and from H-9 to C-5". When 38 was later re-isolated, $\mathrm{X}$-ray crysstallographic analysis led to revised structure $\mathbf{3 8 b} .{ }^{102}$ The MS, ${ }^{1} \mathrm{H}$, and ${ }^{13} \mathrm{C}$ NMR spectroscopic data originally published for $\mathbf{3 8 a}$ were identical to those obtained for $\mathbf{3 8 b}$, prompting the structural revision of $\mathbf{3 8}$. Recently, a biomimetic synthesis of $\mathbf{3 8}$ was reported with agreement between NMR spectroscopic and X-ray crystallographic data of synthetic and natural $\mathbf{3 8 b} .{ }^{103}$ Some originally reported HMBC correlations cannot be rationalized in light of the new structure since the hydrogens and the carbons are separated by $4-6$ bonds. ${ }^{101}$ However, due to the wide spectral window necessary to record a full HMBC spectrum for this compound (0-220 ppm in the indirect dimension), it is likely that the resulting low resolution led to confusion in the assignment of carbons with similar chemical shifts (Fig. 7). 


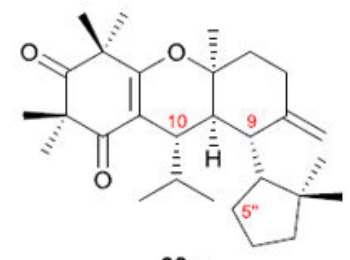

$38 \mathrm{a}$

original structure

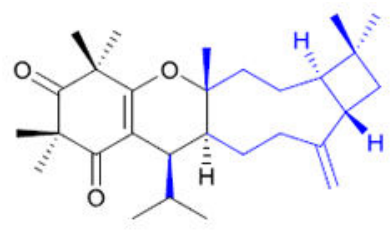

$38 \mathrm{~b}$

revised structure

\section{Structural revision based on NMR spectroscopic analysis and empirical rules}

Quantum chemical computation of spectroscopic parameters as a tool for structural revision is in vogue but it requires powerful computing resources. Sometimes, a careful analysis of NMR chemical shifts and coupling constants of a series of analogues is sufficient to assess the precise configuration of a compound. Identifying potential structure misassignments can be enabled by application of accepted empirical rules. The following proposed revisions illustrate how an understanding of basic principles of NMR spectroscopic analysis and fundamental organic chemistry facilitate correction of structural errors.

\section{$5.12 \beta$-Hydroxynagilactone $F$ and nagilactone I}

The bioactive compounds $2 \beta$-hydroxynagilactone $\mathrm{F}(\mathbf{3 9})$ and nagilactone I (40) were originally isolated from the root bark of the Japanese evergreen Podocarpus nagi. ${ }^{104}$, 105 The proposed structures 39a and 40a included an $\boldsymbol{a}$-hydroxy at C-2, which was established from the half-height width of the H-2 NMR signal and the assumption that ring A adopted a chair conformation (Fig. 8A). ${ }^{106}$ Recently, 39 and $\mathbf{4 0}$ were re-isolated from Ethiopian P. falcatus and were found to be active against human colorectal adenocarcinoma. ${ }^{107}$ Conformational analysis using MM2 force field suggested that a boat conformation at ring A for epimers 39a and 39b, with $2 a$ - and $2 \beta$-hydroxy groups, respectively (Fig. $8 \mathrm{~B}$ ), would have lower energy than the originally proposed chair conformation. ${ }^{107}$ This change in conformation required that the dddd $\mathrm{H}-2$ signal $(J=12.9,10.0,7.2,5.1 \mathrm{~Hz})$ was axially positioned, thus supporting the $\beta$-oriented $\mathrm{C}-2$ hydroxy group in revised 39b. The ${ }^{1} \mathrm{H}$ and 2D-NOESY NMR spectra were analyzed to further support the revised orientation of the hydroxy group at C-2 and Xray crystallographic analysis was used to confirm this new assignment. The absence of a NOESY correlation expected for structure 39a due to a 1,3-diaxial interaction between $\mathrm{H}-2$ and the methyl group at $\mathrm{C}-10$ should have raised red a flag on the validity of the original structure. ${ }^{105}$ 


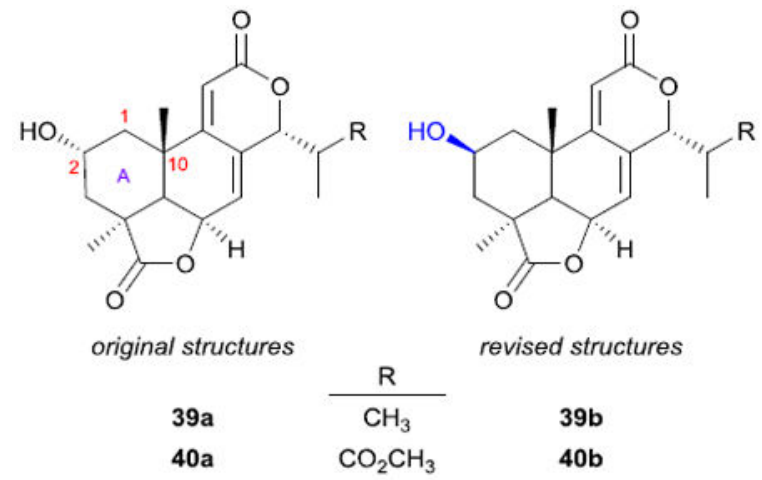

\subsection{Coniothyrione}

Coniothyrione (41) is a chlorinated cyclopentadienylbenzopyrone antibiotic produced by Coniothyrium cerealis, an ascomycete obtained from decaying livestock manure. A mechanistic assay involving interaction with the ribosomal protein small subunit $\mathrm{D}$ was used to guide the isolation of $\mathbf{4 1} .{ }^{108}$ Lack of HMBC correlation between olefinic H-4 and the methoxycarbonyl C-1 was used to support the proposed structure 41a; however, the absence of a correlation does not affirm that they are necessarily more than three bonds apart. ${ }^{14}$ Furthermore, as the $\mathrm{C}-3 / \mathrm{C}-4$ double bond is conjugated to a ketone at $\mathrm{C}-13$, the assignment of C-3 at $\delta_{\mathrm{C}} 127.2$ and C-4 at $\delta_{\mathrm{C}} 143.1$ was unconvincing. ${ }^{109}$ The structure was revised to 41b by interchanging $\delta_{\mathrm{C}}$ between $\mathrm{C}-3 / \mathrm{C}-4$ along with the position of chlorine, whereas the absence of a three bond HMBC correlation from $\mathrm{H}-3$ to $\mathrm{C}-1$ was attributed to an unfavorable dihedral angle. Biosynthetic analysis was also used to support the revised structure 41b.

Although the biosynthetic claim was disputed, the revised structure 41b was ultimately confirmed based on 1,1-ADEQUATE, ${ }^{1} J_{\mathrm{CC}}$-edited HSQC-1,n-ADEQUATE, $J$-modulated ADEQUATE experiments and computational studies. ${ }^{110}$ In a recent study the structure was confirmed using ACD/Structure Elucidator in combination with DFT calculations. ${ }^{14}$
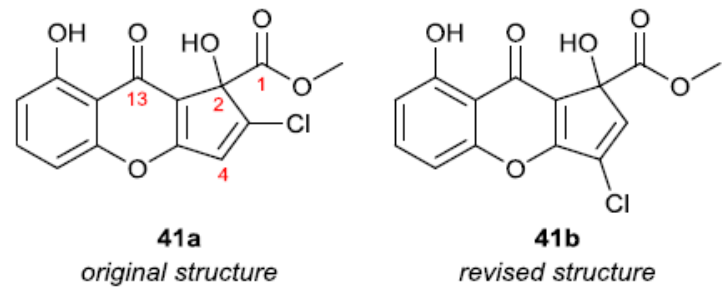

\subsection{Madurastatins}

Madurastatins are siderophores produced by bacteria and fungi that facilitate uptake of essential metals into bacterial cells. ${ }^{111}$ It has been well established that siderophoredependent iron sequestration is essential for the virulence and pathogenicity of some bacteria and fungi. ${ }^{112}$ Antibacterial madurastatins A1 (42) and B1 (43) are produced by Actinomadura madurae, ${ }^{113}$ whereas madurastatin C1 (44) $)^{114}$ and MBJ-0035 (45) $)^{115}$ were isolated from Actinomadura sp. and Streptosporangium sp., respectively. Their structures (42a-43a), proposed based on NMR and mass spectral analysis, featured a unique aziridine ring thought to be essential for their antibacterial activity. ${ }^{113}$ The aziridine ring in the 
original structures 42a-45a was derived from HMBC correlations between a-proton H-19 and $\beta$-methylene protons $\mathrm{H}_{2}-20$ to carbonyls $\mathrm{C}-18$ and C-21 (Fig. 9A). ${ }^{113}$ However, these HMBC correlations are equally justified by a dihydrooxazole moiety (Fig. 9B), which was recently observed in spoxazomicin $\mathrm{C}$ and D. ${ }^{116}$ An aziridine ring carbon has an expected $\delta_{\mathrm{C}}$ of 33-44 ppm while dihydrooxazole $\delta_{\mathrm{C}}$ would be expected further downfield. The experimental values for C-19 and C-20 in 42a were 67.2 and 69.4 ppm, respectively, favoring the dihydrooxazole moiety. ${ }^{113}$ In a recent study, the revised structures were further confirmed by partial synthesis of an aziridine ring, a dihydrooxazole moiety, and comparison of $\delta_{\mathrm{C}}$ at $\mathrm{C}-19$ and $\mathrm{C}-20 .{ }^{117}$

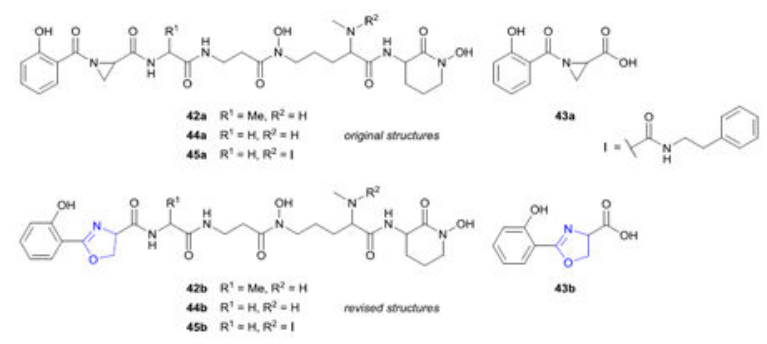

\subsection{Coagulin}

There are over 900 naturally occurring withanolides originating from numerous genera of the plant family Solanaceae that exhibit biological activities including anti-inflammatory, immunomodulatory, antifeedant, and antitumor. ${ }^{118,119}$ Withanolides are steroids that contain a characteristic highly oxygenated ergostane backbone. Comparison of ${ }^{13} \mathrm{C} N \mathrm{NM}$ spectroscopic data from known with-anolides whose structures have been well established by X-ray crystallography and 2D NMR spectroscopy enabled revisions to 29 withanolide structures. ${ }^{120}$ The observations suggested that the $\delta_{\mathrm{C}}$ of C-7, C-9, C-12, and C-21 are shifted, some upfield and others downfield, by the presence of a hydroxy group at C-14 or $\mathrm{C}-17$ via the $\gamma$-gauche effect and that the configuration of the hydroxy groups at C-14 and C-17 can be determined from the $\delta_{\mathrm{C}}$ at C-9, C-12, and C-21. Coagulin (46), a product of the medicinal plant Withania coagulans, ${ }^{121}$ was suggested to contain an uncommon C-14/O/ C-20 bridge (46a), based on the degree of unsaturation as determined by EIMS and the $\delta_{\mathrm{C}}$ of three oxygenated quaternary carbons at C-14, C-17, and C-20. The proposed linkage for 46a requires that the 17-hydroxy group be in a $\beta$-orientation, but it was revised to be in a $a$ orientation as indicated by the upfield chemical shift of C-12. ${ }^{120}$ Further, the ${ }^{13} \mathrm{C}$ NMR spectroscopic data for positions 1-22 of $\mathbf{4 6}$ were almost identical to those of a known analogue, withanolide K. Since $\mathbf{4 6}$ contained the same steroid nucleus as withanolide K, the structure was revised to 27 -hydroxywith-anolide $\mathrm{K}(\mathbf{4 6 b})$. It should also be noted that the authors of the original paper mistakenly concluded the observed $\left[\mathrm{M}-\mathrm{H}_{2} \mathrm{O}\right]^{+}$to be the molecular ion of 46, resulting in an inflated value for degrees of unsaturation. ${ }^{120}$ 

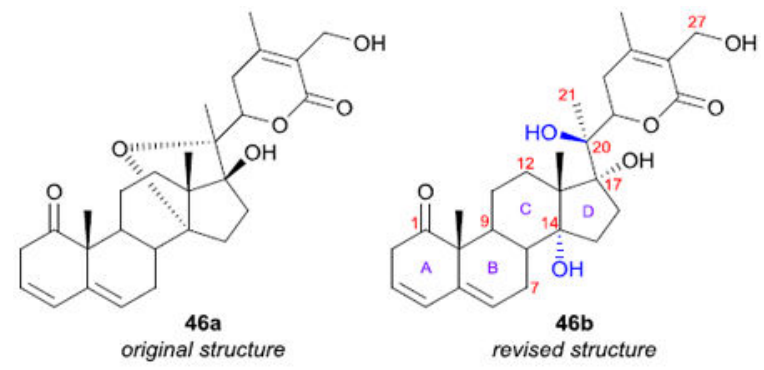

\subsection{Cephalosporolides and penisporolide}

Cephalosporolides H (47) and I (48) and penisporolide B (49) are [5,5]-spiroacetal-cisfused- $\gamma$-lactones originally described following their discovery from a marine-derived Penicillium fungus. ${ }^{122}$ The proposed stereochemistry for cephalosporolide $\mathrm{H}$ (47a) was established by NOESY correlations from H-5a to H-4 and from H-5b to H-7. Penisporolide B was shown to have structure 49a which, if the lateral chain is neglected, is a diastereoisomer of 47a and 48a. In all cases, the relative configuration of the chiral centers at C-3, C-4 and C-6 was supported by NOESY data, but the configuration at C-9, which is relatively distant from positions 3, 4, and 6, was not discussed. Recently, NMR spectroscopic data of the four possible relative stereoisomers of analogues of 47-49 $(\mathrm{R}=$ $\mathrm{Me}$ ) were examined. ${ }^{123}$ By searching for significant patterns in $\delta_{\mathrm{H}}$ and $J$ values, a decision tree was formulated based on three NMR spectroscopic parameters to determine the relative stereochemistry for this compound class: (i) the scalar coupling constants of H-4 with H-3 and $\mathrm{H}_{2}-5$; (ii) the difference in $\delta_{\mathrm{H}}$ between the two $\mathrm{H}-5$ protons, which allows determination of the configuration at C- 6 relative to the orientation of $\mathrm{H}-3 / \mathrm{H}-4$; and (iii) the difference in $\delta_{\mathrm{H}}$ between both protons at position 8 which determines the configuration at C-9, based on arguments of steric compression. ${ }^{124}$ To strengthen the model, the chemical shifts of C-3 and C-7 were also considered. The decision tree was used to confirm the assignment of 21 such molecules from different sources and to revise the structures of cephalosporolide $\mathrm{H}$ (47a) and I (48a) and penisporolide (49a) to $47 \mathbf{b}, 48 b$ and $49 b$, respectively.
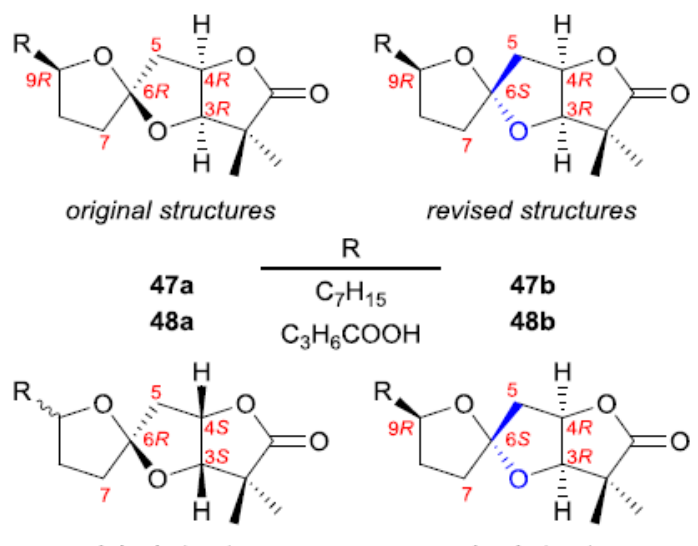

revised structures

original structure
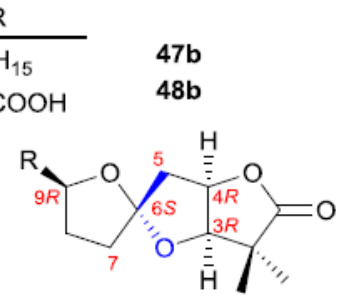

revised structure

49a $\frac{\mathrm{R}}{\mathrm{C}_{2} \mathrm{H}_{4} \mathrm{COC}_{3} \mathrm{H}_{7}}$

$49 b$ 


\subsection{Cryptospirolepine}

The 'Crews rule' states that the structure of a molecule is expected to be especially difficult to solve when the ratio of the number of hydrogens to carbons is fewer than 1, since NMR spectroscopic methods are so dependent on detection through protons. ${ }^{125}$ The polyaromatic alkaloid cryptospirolepine (50) obtained from the West African shrub Cryptolepsis sanguinolenta, certainly falls into this category. ${ }^{126}$ In addition to being proton-deficient, its yield was minimal, increasing the challenging nature of the original structure determination. The validity of structure 50a was called into question when a sealed NMR tube containing degraded product 52 (Fig. 10) was evaluated by members of the same research group 12 years after its report. ${ }^{127}$ In the originally proposed 50a, vinyl proton H-13 was placed near a four-spin aromatic system based on a ROESY correlation with H-12. Additionally, a strong HMBC correlation was observed between H-12 and C-13a, which is unlikely as they are four bonds apart (Fig. 10). ${ }^{126}$ Considering these discrepancies, the structure was revised to 50b, based on long-range HRSQMBC correlations between both $N$-methyl groups and C-2 as well as a weak correlation from H-13 to C-2. ${ }^{127}$ Further analysis of $\mathbf{5 0}$ by a 1,1-HDADEQUATE experiment established that vinyl C-13 is bonded to carbonyl C-2 and quaternary C-13a. In addition, spiro C-1 was shown to interact with C-13 through a ${ }^{2} J_{\mathrm{CC}}$ correlation. The revised structure 50b justifies both degradation products as well as the questionable four bond $\mathrm{HMBC}$ correlation observed in the original proposal. The revision was recently confirmed by the residual dipolar coupling and residual chemical shift anisotropy analysis. ${ }^{128}$

\section{Other cases}

Sometimes, the solution to a structural elucidation problem can be found using traditional strategies such as incorporation of isotopes for biosynthetic studies or targeted degradation. These approaches offer inexpensive alternatives that can be used when sophisticated computational methods and analytical instrumentation are not available. The two last cases are examples falling into this category.

\subsection{Phyllostictine A}

Phyllosticta cirsii is a pathogenic fungus that infects the perennial flowering plant Cirsium arvense and produces phyllostictine A (53). ${ }^{129}$ The molecule was reported to have an unprecedented $Z$ - $a$-(dihydrofuran-3(2H)-yli-dene)- $\beta$-lactam core (53a) which sparked interest about the possibility of a novel biosynthetic pathway. Recently, the structure was revised based on biosynthetic studies whereby feeding experiments incorporated ${ }^{13} \mathrm{C}$ at either $\mathrm{C}-1$ or $\mathrm{C}-2$ of acetate. This revealed that the distribution of carbon was complex in proposed structure 53a but logical in revised structure 53b, which had an alternating pattern for the distribution of ${ }^{13} \mathrm{C}$ atoms consistent with a hybrid polyketide synthase and nonribosomal peptide synthetase biosynthetic pathway (Fig. 11A). ${ }^{130}$ Additionally, NMR spectra acquired for re-isolated $\mathbf{5 3}$ showed some major discrepancies in HMBC correlations with respect to 53a. For example, an HMBC correlation from the methyl protons at C-5 to C-11 would have required 7-8 bond coupling if 53a was correct (Fig. 11B). The new NMR

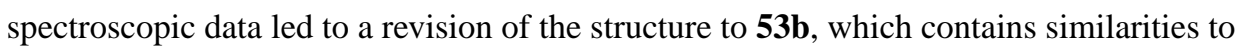
other known, fungal metabolites. ${ }^{131,132 .}$ 

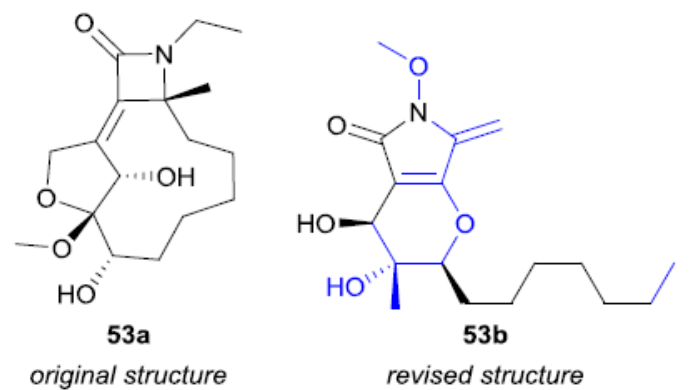

\subsection{Poecillastrin C}

Cytotoxic chondropsintype macrolide lactams, like poecillastrin C (54), are potent natural products that have been obtained from different genera of deep-sea sponges in very small amounts, making it difficult to fully characterize the structures. ${ }^{133}$ A challenging structural aspect of these molecules is establishing which of the two carbonyls of the $\beta$ hydroxyaspartic acid residue forms the ester linkage and which is a carboxylic acid functionality (i.e., position 1 or $\gamma$ ) (Fig. 12). Assignment of these carbonyl moieties was previously attempted with the related molecule chondropsin A. ${ }^{134}$ The free carboxylic acid of chondropsin A was converted to a methyl ester and an NOE was observed between the newly formed $O$-methyl protons and the oxymethine proton $\beta$, which prompted the authors to suggest that $\mathrm{C}-1$ formed the ester linkage. Subsequent structure determination of other chondropsin molecules, including $\mathbf{5 4}$, used the suggested ester linkage provided for chondropsin A, exemplified in $\mathbf{5 4 a} .{ }^{133}$ In a recent study, this strategy was questioned based on the fact that both the $a$-methine and $\beta$-methine protons are close enough to the $O$-methyl protons to produce observable NOEs. ${ }^{135}$ Examination of additional NMR spectroscopic data suggested that the structure of poecillastrin $C$ was as likely to be $\mathbf{5 4 b}$ as $\mathbf{5 4 a}$. To determine whether position 1 or $\gamma$ formed the ester bond, a hydride reduction of the lactam was used as a discriminatory tool due to its greater reactivity towards esters relative to carboxylic acids. If 54a was the correct structure, a reduction followed by an acid hydrolysis would lead to hydroxymethyl $\mathbf{5 5}$, keeping the $\gamma$-carboxylic acid intact while 54b exposed to the same treatment would convert to hydroxymethyl $\mathbf{5 6}$ (Fig. 12). The absolute configuration was established by subjecting the acid hydrolysate of $\mathbf{5 4}$ to Marfey's derivatization and comparing it to synthetic standards of $\beta$-hydroxyaspartic acid treated with Marfey's reagent. The $\beta$-hydroxyaspartic acid residue liberated from poecillastrin $\mathrm{C}$ was found to be ( $2 R$, $3 R$ )-2-amino-3,4-dihydroxybutanoic acid, supporting the hypothesis that the $\gamma$-carboxyl group is esterified, consistent with revised structure $\mathbf{5 4 b}$. 


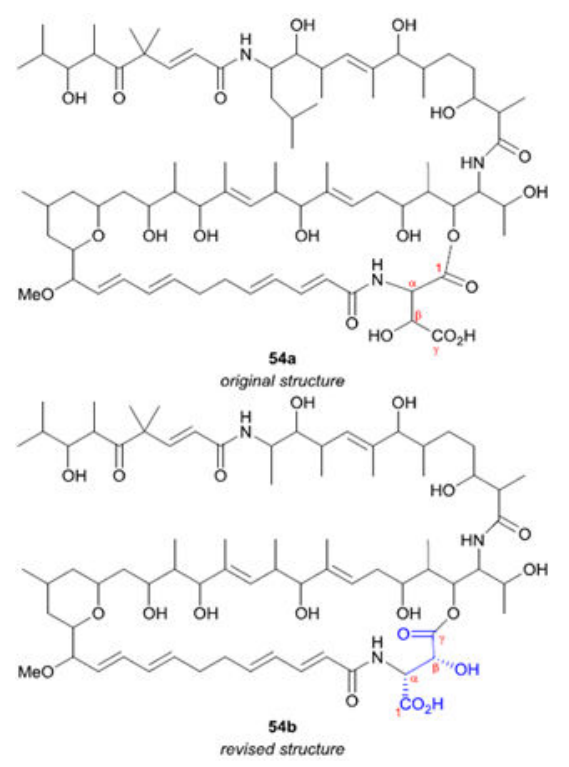

\section{Conclusions}

Despite substantial advances in modern spectroscopic methods and computational tools, natural product structure determination is still heavily reliant on the careful observations and well-informed interpretations of individual scientists. In fact, errors in structural assignments almost always arise from the failure to recognize multiple possible molecular structures as testable hypotheses. When one instead imagines a single structural solution for a natural product and then proceeds to assemble data or models aimed at confirming the hypothetical structure, the chance of error is high (much like in criminal detective work). A safer approach is to imagine as many structural solutions as possible for a given case and then design experiments, collecting data and building models, to test the feasibility of each, leaving only the best hypothesis standing as the most likely structure while weighing the weaknesses of each.

There are several important lessons that can be learned from these cases of mistaken identity. For instance, the identification of unusual structural features should be carefully confirmed to avoid proposing an incorrect structure. In addition, a thorough reading of the literature can provide important information about existing precedents that can guide structural characterization. However, it is important to carefully assess and question literature precedents, as structural errors can be propagated. Extra care should be taken when applying derivatization and hydrolysis techniques for structure elucidation as these chemical manipulations can lead to epimerization or unexpected side reactions, as seen with the brevianamides. ${ }^{76}$ When NMR spectroscopic data present the challenge of signal overlap and unsatisfactory signal dispersion, meticulous interpretation in conjunction with computational modeling can aid in avoiding mistakes. Additionally, 2D band-selective NMR spectra that reduce the spectral window to focus on the region of signal overlap can enhance spectral resolution. $J$-based configurational analysis can be used to rule out errors, as seen with the glabramycins. ${ }^{38}$ Comparison of experimental data to calculated spectroscopic properties such as ${ }^{13} \mathrm{C}$ and ${ }^{1} \mathrm{H}$ NMR, ECD, VCD and optical rotation, can confirm the proposed 
structures and resolve errors. Computer-Assisted Structure Elucidation (CASE) algorithms have emerged as a promising tool that generates a set of possible structures based on experimental NMR features provided. Finally, with computational tools being increasingly accessible, all natural product chemists can utilize them as part of structure elucidation.

\section{Acknowledgments}

We gratefully acknowledge Dr. William F. Reynolds for his valuable insights that improved the manuscript. We also thank the U.S. National Institutes of Health (ICBG U19-TW007401) for financial support of our natural product structure determination research.

\section{References}

1. Newman DJ, Cragg GM. J Nat Prod. 2016; 79:629-661. DOI: 10.1021/acs.jnatprod.5b01055 [PubMed: 26852623]

2. Jackson PA, Widen JC, Harki DA, Brummond KM. J Med Chem. 2016; 60:839-885. DOI: 10.1021/ acs.jmedchem.6b00788 [PubMed: 27996267]

3. Rodrigues T, Reker D, Schneider P, Schneider G. Nat Chem. 2016; 8:531-541. DOI: 10.1038/ nchem.2479 [PubMed: 27219696]

4. Jacob NT, Lockner JW, Kravchenko VV, Janda KD. Angew Chem Int Ed. 2014; 53:6628-6631. DOI: 10.1002/anie.201402133

5. Borman S. Chemical \& Engineering News. 2017; 95:7.

6. Nicolaou K, Snyder SA. Angew Chem Int Ed. 2005; 44:1012-1044. DOI: 10.1002/anie.200460864

7. Bragg WH. Proc Phys Soc London. 1921; 34:33-50. DOI: 10.1088/1478-7814/34/1/306

8. Lonsdale K. Nature. 1928; 122:810.doi: 10.1038/122810c0

9. Li J, Burgett AWG, Esser L, Amezcua C, Harran PG. Angew Chem Int Ed. 2001; 40:4770-4773. DOI: 10.1002/1521-3773(20011217)40:24<4770::AID-ANIE4770>3.0.CO;2-T

10. Breton RC, Reynolds WF. Nat Prod Rep. 2013; 30:501-524. DOI: 10.1039/c2np20104f [PubMed: 23291908]

11. Lodewyk MW, Siebert MR, Tantillo DJ. Chem Rev. 2011; 112:1839-1862. DOI: 10.1021/ cr200106v [PubMed: 22091891]

12. Berova, N., Polavarapu, PL., Nakanishi, K., Woody, RW. Comprehensive chiroptical spectroscopy, applications in stereochemical analysis of synthetic compounds, natural products, and biomolecules. John Wiley \& Sons; 2012.

13. Nakanishi, K. A wandering natural products chemist. American Chemical Society; 1991.

14. Buevich AV, Elyashberg ME. J Nat Prod. 2016; 79:3105-3116. DOI: 10.1021/acs.jnatprod. 6b00799 [PubMed: 28006916]

15. Maier ME. Nat Prod Rep. 2009; 26:1105-1124. DOI: 10.1039/b809658a [PubMed: 19693411]

16. Brown PD, Lawrence AL. Nat Prod Rep. 2017; 34:1193-1202. DOI: 10.1039/C7NP00025A [PubMed: 28850146]

17. Suyama TL, Gerwick WH, McPhail KL. Bioorg Med Chem. 2011; 19:6675-6701. DOI: 10.1016/ j.bmc.2011.06.011 [PubMed: 21715178]

18. Bühl M, van Mourik T. Wiley Interdiscip Rev Comput Mol Sci. 2011; 1:634-647. DOI: 10.1002/ wcms.63

19. Bagno A, Saielli G. Wiley Interdiscip Rev Comput Mol Sci. 2015; 5:228-240. DOI: 10.1002/ wcms. 1214

20. Grimblat N, Sarotti AM. Chem Eur J. 2016; 22:12246-12261. DOI: 10.1002/chem.201601150 [PubMed: 27405775]

21. Sims JJ, Lin GHY, Wing RM. Tetrahedron Lett. 1974; 15:3487-3490. DOI: 10.1016/ S0040-4039(01)91944-6

22. Gonzalez AG, Martin JD, Martin VS, Perez R, Tagle B, Clardy J. J Chem Soc Chem Commun. 1985; :260-261.doi: 10.1039/C39850000260 
23. De Carvalho LR, Fujii MT, Roque NF, Kato MJ, Lago JHG. Tetrahedron Lett. 2003; 44:26372640. DOI: 10.1016/S0040-4039(03)00379-4

24. de Carvalho LR, Fujii MT, Roque NF, Lago JHG. Phytochemistry. 2006; 67:1331-1335. DOI: 10.1016/j.phytochem.2006.04.020 [PubMed: 16766002]

25. Crimmins MT, Hughes CO. Org Lett. 2012; 14:2168-2171. DOI: 10.1021/ol3007259 [PubMed: 22472027]

26. Takahashi S, Yasuda M, Nakamura T, Hatano K, Matsuoka K, Koshino H. J Org Chem. 2014; 79:9373-9380. DOI: 10.1021/jo501228v [PubMed: 25216028]

27. Koichi S, Arisaka M, Koshino H, Aoki A, Iwata S, Uno T, Satoh H. J Chem Inf Model. 2014; 54:1027-1035. DOI: 10.1021/ci400601c [PubMed: 24655374]

28. Mukhina OA, Koshino H, Crimmins MT, Kutateladze AG. Tetrahedron Lett. 2015; 56:4900-4903. DOI: $10.1016 / j . t e t l e t .2015 .06 .078$

29. Silverstein, RM., Webster, FX., Kiemle, DJ. Spectrometric Identification of Organic Compounds. 7. John Wiley \& Sons; Hoboken, NJ: 2005.

30. Shiraiwa K, Yuan S, Fujiyama A, Matsuo Y, Tanaka T, Jiang ZH, Kouno I. J Nat Prod. 2012; 75:88-92. DOI: 10.1021/np2007582 [PubMed: 22185651]

31. González-Márquez V, Cruz-Gregorio S, Sandoval-Lira J, Quintero L, Sartillo-Piscil F. Tetrahedron Lett. 2015; 56:5416-5418. DOI: 10.1016/j.tetlet.2015.08.003

32. Kutateladze AG. J Org Chem. 2016; 81:8659-8661. DOI: 10.1021/acs.joc.6b01855 [PubMed: 27580472]

33. Chen JY, Huang CY, Lin YS, Hwang TL, Wang WL, Chiou SF, Sheu JH. J Nat Prod. 2016; 79:2315-2323. DOI: 10.1021/acs.jnatprod.6b00452 [PubMed: 27536968]

34. Kutateladze AG, Reddy DS. J Org Chem. 2017; 82:3368-3381. DOI: 10.1021/acs.joc.7b00188 [PubMed: 28339201]

35. González AG, Martín JD, Martín VS, Norte M. Tetrahedron Lett. 1979; 20:2719-2722. DOI: 10.1016/S0040-4039(01)86397-8

36. Jayasuriya H, Zink D, Basilio A, Vicente F, Collado J, Bills G, Goldman ML, Motyl M, Huber J, Dezeny G, Byrne K, Singh SB. J Antibiot. 2009; 62:265-269. DOI: 10.1038/ja.2009.26 [PubMed: 19343064]

37. Bugni TS, Janso JE, Williamson RT, Feng X, Bernan VS, Greenstein M, Carter GT, Maiese WM, Ireland CM. J Nat Prod. 2004; 67:1396-1399. DOI: 10.1021/np049973t [PubMed: 15332862]

38. Li Y. RSC Advances. 2015; 5:36858-36864. DOI: 10.1039/c5ra01753j

39. Ishigami K, Yamamoto M, Watanabe H. Tetrahedron Lett. 2015; 56:6290-6293. DOI: 10.1016/ j.tetlet.2015.09.149

40. Yamamoto M, Ishigami K, Watanabe H. Tetrahedron. 2017; 73:3271-3280. DOI: 10.1016/j.tet. 2017.04.061

41. Matsumori N, Kaneno D, Murata M, Nakamura H, Tachibana K. J Org Chem. 1999; 64:866-876. DOI: 10.1021/jo981810k [PubMed: 11674159]

42. Collett LA, Davies-Coleman MT, Rivett DEA. Phytochemistry. 1998; 48:651-656. DOI: 10.1016/ S0031-9422(97)01075-3

43. García-Fortanet J, Murga J, Carda M, Marco JA. Arkivoc. 2005; 2005:175-188. DOI: 10.3998/ark. 5550190.0006 .918

44. Sabitha G, Gopal P, Reddy CN, Yadav JS. Tetrahedron Lett. 2009; 50:6298-6302. DOI: 10.1016/ j.tetlet.2009.08.109

45. Juárez-González F, Suárez-Ortiz GA, Fragoso-Serrano M, Cerda-García-Rojas CM, PeredaMiranda R. Magn Reson Chem. 2015; 53:203-212. DOI: 10.1002/mrc.4178 [PubMed: 25353378]

46. Frisch MJ, Trucks GW, Schlegel HB, Scuseria GE, Robb MA, Cheeseman JR, Scalmani G, Barone V, Mennucci B, Petersson GA, Nakatsuji H, Caricato M, Li X, Hratchian HP, Izmaylov AF, Bloino J, Zheng G, Sonnenberg JL, Hada M, Ehara M, Toyota K, Fukuda R, Hasegawa J, Ishida M, Nakajima T, Honda Y, Kitao O, Nakai H, Vreven T, M JA Jr, Peralta JE, Ogliaro F, Bearpark M, Heyd JJ, Brothers E, Kudin KN, Staroverov VN, Keith T, Kobayashi R, Normand J, Raghavachari K, Rendell A, Burant JC, Iyengar SS, Tomasi J, Cossi M, Rega N, Millam JM, Klene M, Knox JE, Cross JB, Bakken V, Adamo C, Jaramillo J, Gomperts R, Stratmann RE, Yazyev O, Austin AJ, 
Cammi R, Pomelli C, Ochterski JW, Martin RL, Morokuma K, Zakrzewski VG, Voth GA, Salvador P, Dannenberg JJ, Dapprich S, Daniels AD, Farkas O, Foresman JB, Ortiz JV, Cioslowski J, Fox DJ. Gaussian 09, Revision D.01. 2013

47. Deng W, Cheeseman JR, Frisch MJ. J Chem Theory Comput. 2006; 2:1028-1037. DOI: 10.1021/ ct600110u [PubMed: 26633062]

48. Molinski TF, Morinaka BI. Tetrahedron. 2012; 68:9307-9343. DOI: 10.1016/j.tet.2011.12.070 [PubMed: 23814320]

49. Evans DA, Rieger DL, Gage JR. Tetrahedron Lett. 1990; 31:7099-7100. DOI: 10.1016/ S0040-4039(00)97250-2

50. Rychnovsky SD, Yang G, Powers JP. J Org Chem. 1993; 58:5251-5255. DOI: 10.1021/ jo00071a040

51. Sun Y, Zhao Z, Feng Q, Xu Q, Lü L, Liu JK, Zhang L, Wu B, Li YQ. Helv Chim Acta. 2013; 96:76-84. DOI: $10.1002 / \mathrm{hlca} .201200068$

52. Reddy DS, Kutateladze AG. Org Lett. 2016; 18:4860-4863. DOI: 10.1021/acs.orglett.6b02341 [PubMed: 27611774]

53. Bisson J, Simmler C, Chen S-N, Friesen JB, Lankin DC, McAlpine JB, Pauli GF. Nat Prod Rep. 2016; 33:1028-1033. DOI: 10.1039/c6np00022c [PubMed: 27197893]

54. Chacón-Morales PA, Amaro-Luis JM. Tetrahedron Lett. 2016; 57:2713-2716. DOI: 10.1016/ j.tetlet.2016.04.116

55. Reddy DS, Kutateladze AG. Tetrahedron Lett. 2016; 57:4727-4729. DOI: 10.1016/j.tetlet. 2016.09.030

56. MacKinnon SL, Keifer P, Ayer WA. Phytochemistry. 1999; 51:215-221. DOI: 10.1016/ S0031-9422(98)00732-8

57. Pedras MSC, Chumala PB, Jin W, Islam MS, Hauck DW. Phytochemistry. 2009; 70:394-402. DOI: 10.1016/j.phytochem.2009.01.005 [PubMed: 19223049]

58. Kenmoku H, Takeue S, Oogushi M, Yagi Y, Sassa T, Toyota M, Asakawa Y. Nat Prod Commun. 2014; 9:351-354. [PubMed: 24689212]

59. Takahashi M, Kawamura A, Kato N, Nishi T, Hamachi I, Ohkanda J. Angew Chem Int Ed. 2012; 51:509-512. DOI: 10.1002/anie.201106995

60. Miyake T, Honma Y, Urano T, Kato N, Suzumiya J. Int J Oncol. 2015; 47:315-324. DOI: 10.3892/ ijo.2015.2979 [PubMed: 25936828]

61. Bunney TD, De Boer AH, Levin M. Development. 2003; 130:4847-4858. DOI: 10.1242/dev.00698 [PubMed: 12930777]

62. Skwarczynska M, Molzan M, Ottmann C. Proc Natl Acad Sci. 2013; 110:E377-E386. DOI: 10.1073/pnas.1212990110 [PubMed: 23269842]

63. Lou J, Fu L, Peng Y, Zhou L. Molecules. 2013; 18:5891-5935. DOI: 10.3390/molecules18055891 [PubMed: 23698046]

64. Tang Y, Xue Y, Du G, Wang J, Liu J, Sun B, Li XN, Yao G, Luo Z, Zhang Y. Angew Chem Int Ed. 2016; 55:4069-4073. DOI: 10.1002/anie.201600313

65. Ciochina R, Grossman RB. Chem Rev. 2006; 106:3963-3986. DOI: 10.1021/cr0500582 [PubMed: 16967926]

66. Velingkar VS, Gupta GL, Hegde NB. Phytochem Rev. 2017; 16:725-744. DOI: 10.1007/ s11101-017-9503-7

67. Weng JR, Tsao LT, Wang JP, Wu RR, Lin CN. J Nat Prod. 2004; 67:1796-1799. DOI: 10.1021/ np049811x [PubMed: 15568764]

68. Yang XW, Yang J, Xu G. J Nat Prod. 2017; 80:108-113. DOI: 10.1021/acs.jnatprod.6b00754 [PubMed: 28033006]

69. Allenmark SG. Nat Prod Rep. 2000; 17:145-155. DOI: 10.1039/A809629E [PubMed: 10821109]

70. Batista JM Jr, Blanch EW, Bolzani VdS. Nat Prod Rep. 2015; 32:1280-1302. DOI: 10.1039/ C5NP00027K [PubMed: 26140548]

71. Ovenden SP, Nielson JL, Liptrot CH, Willis RH, Tapiolas DM, Wright AD, Motti CA. Marine Drugs. 2011; 9:2469-2478. DOI: 10.3390/md9112469 [PubMed: 22163196]

72. Li S-M. Nat Prod Rep. 2010; 27:57-78. DOI: 10.1039/B909987P [PubMed: 20024094] 
73. Fdhila F, Vázquez V, Sánchez JL, Riguera R. J Nat Prod. 2003; 66:1299-1301. DOI: 10.1021/ np030233e [PubMed: 14575426]

74. de Carvalho MP, Abraham W-R. Curr Med Chem. 2012; 19:3564-3577. DOI: 10.2174/092986712801323243 [PubMed: 22709011]

75. Li GY, Yang T, Luo YG, Chen XZ, Fang DM, Zhang GL. Org Lett. 2009; 11:3714-3717. DOI: 10.1021/ol901304y [PubMed: 19627104]

76. Ren J, Li GY, Shen L, Zhang GL, Nafie LA, Zhu HJ. Tetrahedron. 2013; 69:10351-10356. DOI: 10.1016/j.tet.2013.10.004

77. Fernandes A, Fernandes I, Cruz L, Mateus N, Cabral M, de Freitas V. J Agric Food Chem. 2009; 57:11154-11160. DOI: 10.1021/jf902093m [PubMed: 19888728]

78. Auzanneau C, Montaudon D, Jacquet R, Puyo S, Pouységu L, Deffieux D, Elkaoukabi-Chaibi A, De Giorgi F, Ichas F, Quideau S, Pourquier P. Molecular Pharmacology. 2012; 82:134-141. DOI: 10.1124/mol.111.077537 [PubMed: 22528119]

79. Mayer W, Gabler W, Riester A, Korger H. Justus Liebigs Annalen der Chemie. 1967; 707:177181. DOI: 10.1002/jlac.19677070125

80. Mayer W, Seitz H, Jochims JC. Justus Liebigs Annalen der Chemie. 1969; 721:186-193. DOI: 10.1002/jlac.19697210123 [PubMed: 5800717]

81. Mayer W, Seitz H, Jochims JC, Schauerte K, Schilling G. Justus Liebigs Annalen der Chemie. 1971; 751:60-68. DOI: 10.1002/jlac.19717510108

82. Nonaka G-I, Ishimaru K, Watanabe M, Nishioka I, Yamauchi T, Wan ASC. Chem Pharm Bull. 1987; 35:217-220. DOI: 10.1248/cpb.35.217

83. Vivas N, Laguerre M, Glories Y, Bourgeois G, Vitry C. Phytochemistry. 1995; 39:1193-1199. DOI: 10.1016/0031-9422(95)00148-Z

84. Matsuo Y, Wakamatsu H, Omar M, Tanaka T. Org Lett. 2015; 17:46-49. DOI: 10.1021/ol503212v [PubMed: 25496565]

85. Vivas N, Laguerre M, Pianet de Boissel I, Vivas de Gaulejac N, Nonier M-F. J Agric Food Chem. 2004; 52:2073-2078. DOI: 10.1021/jf030460m [PubMed: 15053554]

86. Schliemann W, Schneider B, Wray V, Schmidt J, Nimtz M, Porzel A, Böhm H. Phytochemistry. 2006; 67:191-201. DOI: 10.1016/j.phytochem.2005.11.002 [PubMed: 16376394]

87. Tatsis EC, Schaumlöffel A, Warskulat AC, Massiot G, Schneider B, Bringmann G. Org Lett. 2013; 15:156-159. DOI: 10.1021/ol303211w [PubMed: 23249326]

88. Faulkner DJ. Nat Prod Rep. 2001; 18:1-49. DOI: 10.1039/b006897g [PubMed: 11245399]

89. Hoye TR, Alarif WM, Basaif SS, Abo-Elkarm M, Hamann MT, Wahba AE, Ayyad SEN. Arkivoc. 2015; 2015:164-175. DOI: 10.3998/ark.5550190.p008.948 [PubMed: 26835518]

90. Rudi A, Afanii R, Gravalos LG, Aknin M, Gaydou E, Vacelet J, Kashman Y. J Nat Prod. 2003; 66:682-685. DOI: 10.1021/np020589a [PubMed: 12762807]

91. Santos EA, Quintela AL, Ferreira EG, Sousa TS, Pinto FDCL, Hajdu E, Carvalho MS, Salani S, Rocha DD, Wilke DV, Torres MDCM, Jimenez PC, Silveira ER, La Clair JJ, Pessoa ODL, CostaLotufo LV. J Nat Prod. 2015; 78:996-1004. DOI: 10.1021/np5008944 [PubMed: 25879576]

92. Kushlan DM, Faulkner DJ. J Nat Prod. 1991; 54:1451-1454. DOI: 10.1021/np50077a043 [PubMed: 1800643]

93. Xu Z-J, Tan D-X, Wu Y. Org Lett. 2015; 17:5092-5095. DOI: 10.1021/acs.orglett.5b02599 [PubMed: 26434640]

94. Jiménez-Romero C, Rode JE, Rodríguez AD. Tetrahedron: Asymmetry. 2016; 27:410-419. DOI: 10.1016/j.tetasy.2016.03.011 [PubMed: 28190935]

95. Flack HD, Bernardinelli G. Chirality. 2008; 20:681-690. DOI: 10.1002/chir.20473 [PubMed: 17924422]

96. Inokuma Y, Yoshioka S, Ariyoshi J, Arai T, Hitora Y, Takada K, Matsunaga S, Rissanen K, Fujita M. Nature. 2013; 495:461-466. DOI: 10.1038/nature11990 [PubMed: 23538828]

97. Dias DA, Urban S. Phytochemistry. 2011; 72:2081-2089. DOI: 10.1016/j.phytochem.2011.06.012 [PubMed: 21802699]

98. Lee S, Hoshino M, Fujita M, Urban S. Chem Sci. 2017; 8:1547-1550. DOI: 10.1039/c6sc04288k [PubMed: 28572911] 
99. Inokuma Y, Yoshioka S, Ariyoshi J, Arai T, Fujita M. Nat Protoc. 2014; 9:246-252. DOI: 10.1038/ nprot.2014.007 [PubMed: 24407353]

100. Alipour G, Dashti S, Hosseinzadeh H. Phytother Res. 2014; 28:1125-1136. DOI: 10.1002/ptr. 5122 [PubMed: 24497171]

101. Cottiglia F, Casu L, Leonti M, Caboni P, Floris C, Busonera B, Farci P, Ouhtit A, Sanna G. J Nat Prod. 2012; 75:225-229. DOI: 10.1021/np2009219 [PubMed: 22276775]

102. Liu C, Ang S, Huang X-J, Tian H-Y, Deng Y-Y, Zhang D-M, Wang Y, Ye W-C, Wang L. Org Lett. 2016; 18:4004-4007. DOI: 10.1021/acs.orglett.6b01817 [PubMed: 27471772]

103. Lv L, Li Y, Zhang Y, Xie Z. Tetrahedron. 2017; 73:3691-3695. DOI: 10.1016/j.tet.2017.05.007

104. Ying B-P, Kubo I, Chairul Matsumoto T, Hayashi Y. Phytochemistry. 1990; 29:3953-3955. DOI: 10.1016/0031-9422(90)85374-O

105. Kubo I, Himejima M, Ying B-P. Phytochemistry. 1991; 30:1467-1469. DOI: 10.1016/0031-9422(91)84188-X

106. Hayashi Y, Yúiki YI, Matsumoto T, Sakan T. Tetrahedron Lett. 1977; 18:3637-3640. DOI: 10.1016/S0040-4039(01)83313-X

107. Addo EM, Chai HB, Hymete A, Yeshak MY, Slebodnick C, Kingston DG, Rakotondraibe LH. J Nat Prod. 2015; 78:827-835. DOI: 10.1021/np501062f [PubMed: 25807242]

108. Ondeyka JG, Zink D, Basilio A, Vicente F, Bills G, Diez MT, Motyl M, Dezeny G, Byrne K, Singh SB. J Nat Prod. 2007; 70:668-670. DOI: 10.1021/np060557d [PubMed: 17346074]

109. Kong F, Zhu T, Pan W, Tsao R, Pagano TG, Nguyen B, Marquez B. Magn Reson Chem. 2012; 50:829-833. DOI: 10.1002/mrc.3892 [PubMed: 23135875]

110. Martin GE, Buevich AV, Reibarkh M, Singh SB, Ondeyka JG, Williamson RT. Magn Reson Chem. 2013; 51:383-390. DOI: 10.1002/mrc.3952 [PubMed: 23674343]

111. Hider RC, Kong X. Nat Prod Rep. 2010; 27:637-657. DOI: 10.1039/b906679a [PubMed: 20376388]

112. Ji C, Juárez-Hernández RE, Miller MJ. Future Med Chem. 2012; 4:297-313. DOI: 10.4155/fmc. 11.191 [PubMed: 22393938]

113. Harada K-I, Tomita K, Fujii K, Masuda K, Mikami Y, Yazawa K, Komaki H. J Antibiot. 2004; 57:125-135. DOI: 10.7164/antibiotics.57.125 [PubMed: 15112961]

114. Mazzei E, Iorio M, Maffioli SI, Sosio M, Donadio S. J Antibiot. 2012; 65:267.doi: 10.1038/ja. 2012.10 [PubMed: 22377537]

115. Kawahara T, Itoh M, Izumikawa M, Sakata N, Tsuchida T, Shin-ya K. J Antibiot. 2014; 67:577.doi: 10.1038/ja.2014.19 [PubMed: 24619229]

116. Shaaban KA, Saunders MA, Zhang Y, Tran T, Elshahawi SI, Ponomareva LV, Wang X, Zhang J, Copley GC, Sunkara M. J Nat Prod. 2016; 80:2-11. DOI: 10.1021/acs.jnatprod.6b00948 [PubMed: 28029795]

117. Tyler AR, Mosaei H, Morton S, Waddell PG, Wills C, McFarlane W, Gray J, Goodfellow M, Errington J, Allenby N. J Nat Prod. 2017; 80:1558-1562. DOI: 10.1021/acs.jnatprod.7b00082 [PubMed: 28398740]

118. Chen L-X, He H, Qiu F. Nat Prod Rep. 2011; 28:705-740. DOI: 10.1039/C0NP00045K [PubMed: 21344104]

119. Zhang H, Samadi Abbas K, Cohen Mark S, Timmermann Barbara N. Pure Appl Chem. 2012; 84:1353.doi: 10.1351/PAC-CON-11-10-08 [PubMed: 24098060]

120. Zhang H, Timmermann BN. J Nat Prod. 2016; 79:732-742. DOI: 10.1021/acs.jnatprod.5b00648 [PubMed: 26894655]

121. Abbas, Atta-ur-Rahman S., Jamal, Dur-e-Shahwar SA., Choudhary, MI. J Nat Prod. 1993; 56:1000-1006. DOI: 10.1021/np50097a003

122. Li X, Sattler I, Lin W. J Antibiot. 2007; 60:191-195. DOI: 10.1038/ja.2007.21 [PubMed: 17446691]

123. Wang J, Tong R. Org Chem Front. 2017; 4:140-146. DOI: 10.1039/c6qo00556j

124. Cooper MA, Manatt SL. J Am Chem Soc. 1970; 92:4646-4652. DOI: 10.1021/ja00718a029

125. White KN, Amagata T, Oliver AG, Tenney K, Wenzel PJ, Crews P. J Org Chem. 2008; 73:87198722. DOI: 10.1021/jo800960w [PubMed: 18925788] 
126. Tackie AN, Boye GL, Sharaf MHM, Schiff PL, Crouch RC, Spitzer TD, Johnson RL, Dunn J, Minick D, Martin GE. J Nat Prod. 1993; 56:653-670. DOI: 10.1021/np50095a001

127. Saurí J, Bermel W, Buevich AV, Sherer EC, Joyce LA, Sharaf MHM, Schiff PL, Parella T, Williamson RT, Martin GE. Angew Chem Int Ed. 2015; 54:10160-10164. DOI: 10.1002/anie. 201502540

128. Liu Y, Sauri J, Mevers E, Peczuh MW, Hiemstra H, Clardy J, Martin GE, Williamson RT. Science. 2017; 356doi: 10.1126/science.aam5349

129. Evidente A, Cimmino A, Andolfi A, Vurro M, Zonno MC, Cantrell CL, Motta A. Tetrahedron. 2008; 64:1612-1619. DOI: 10.1016/j.tet.2007.12.010

130. Trenti F, Cox RJ. J Nat Prod. 2017; doi: 10.1021/acs.jnatprod.7b00183

131. Li C-S, Ding Y, Yang B-J, Miklossy G, Yin H-Q, Walker LA, Turkson J, Cao S. Org Lett. 2015; 17:3556-3559. DOI: 10.1021/acs.orglett.5b01650 [PubMed: 26107089]

132. Maloney KN, Hao W, Xu J, Gibbons J, Hucul J, Roll D, Brady SF, Schroeder FC, Clardy J. Org Lett. 2006; 8:4067-4070. DOI: 10.1021/o1061556f [PubMed: 16928075]

133. Takada K, Choi BW, Rashid MA, Gamble WR, Cardellina JH 2nd, Van QN, Lloyd JR, McMahon JB, Gustafson KR. J Nat Prod. 2007; 70:428-431. DOI: 10.1021/np0604984 [PubMed: 17378533]

134. Cantrell CL, Gustafson KR, Cecere MR, Pannell LK, Boyd MR. J Am Chem Soc. 2000; 122:8825-8829. DOI: 10.1021/ja0010711

135. Irie R, Takada K, Ise Y, Ohtsuka S, Okada S, Gustafson KR, Matsunaga S. Org Lett. 2017; 19:5395-5397. DOI: 10.1021/acs.orglett.7b02835 [PubMed: 28956931] 


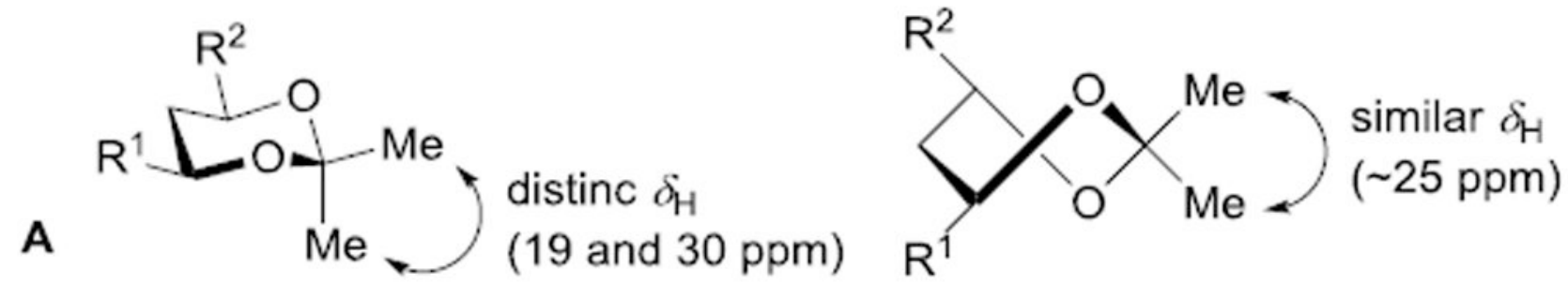

acetonide from a

acetonide from a

syn 1,3-diol anti 1,3-diol

B

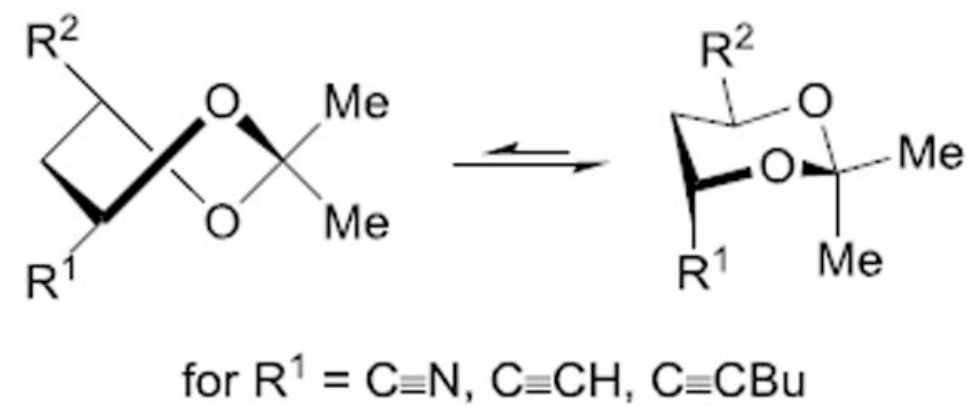

Fig. 1.

(A) Acetonide methodology for configuration assignment of 1,3-diols. (B) Misleading configuration assignment for acetonide from anti 1,3-diols 


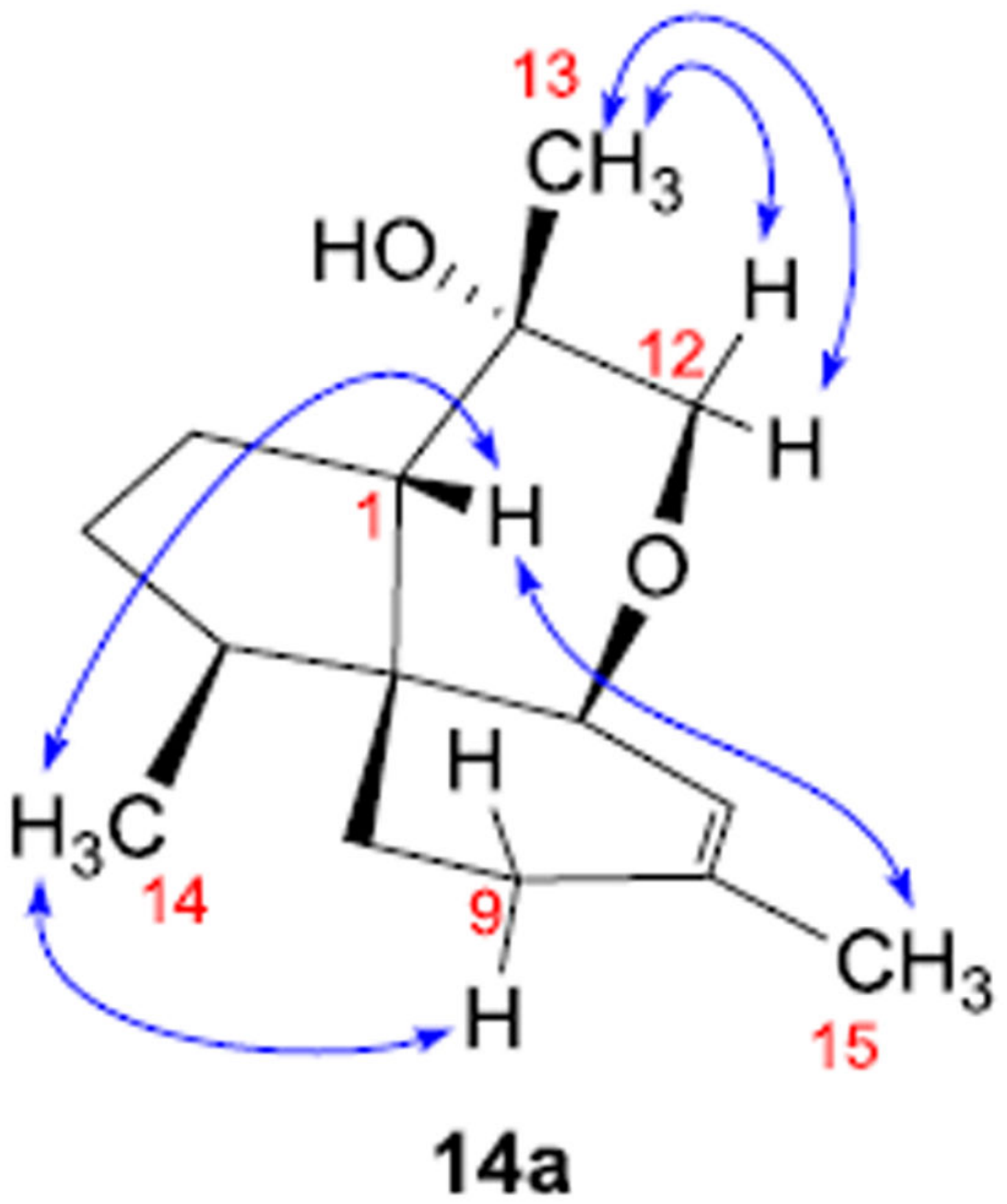

Fig. 2.

NOESY correlations reported for the original cordycepol A structure (14a). 

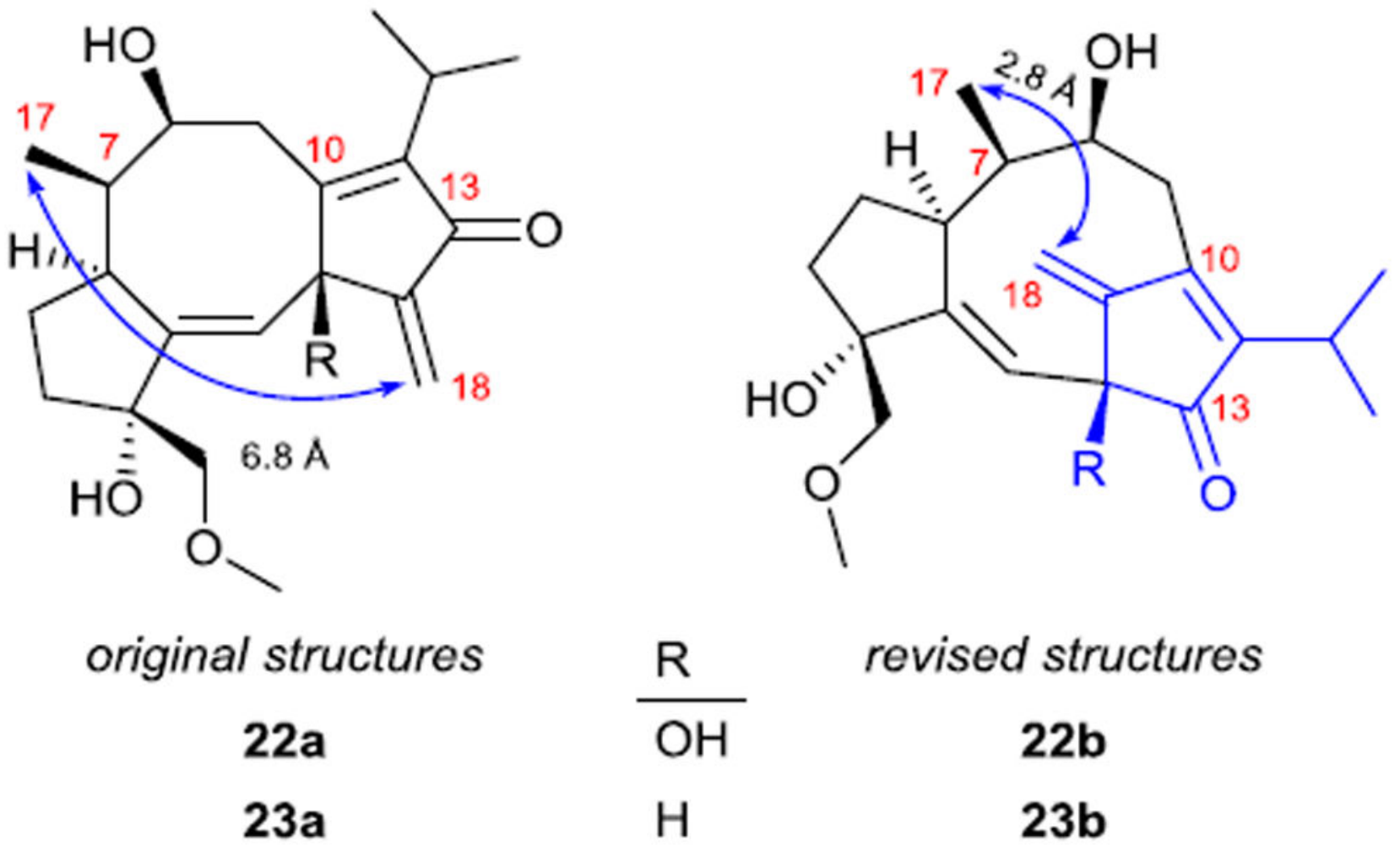

revised structures

22b

Fig. 3.

Original and revised structure showing a key NOE enhancement. 


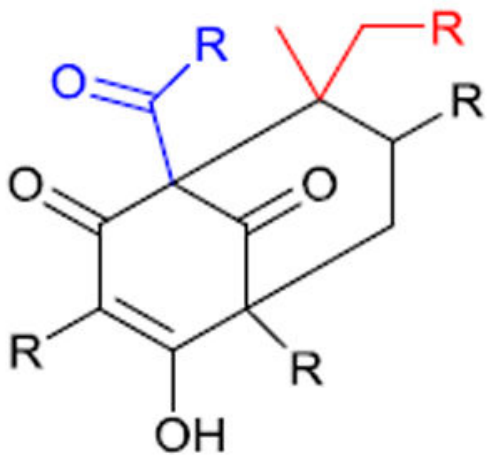

Type A

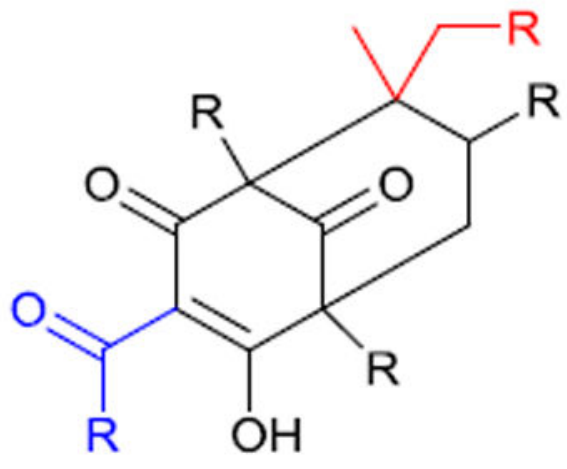

Type B

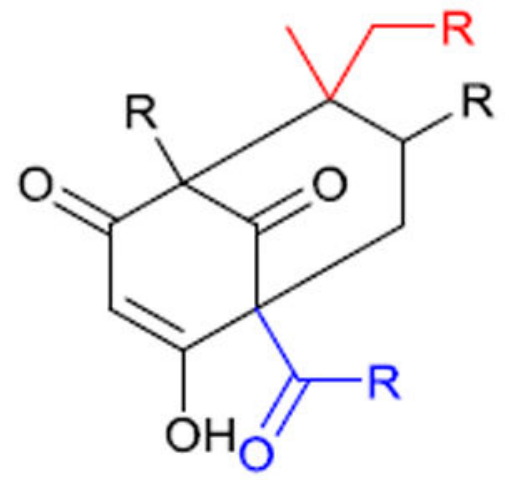

Type C

Fig. 4.

Categories of polycyclic polyprenylated acylphloroglucinol are based on the relative position of the acyl moiety (blue) and the quaternary center (red). 


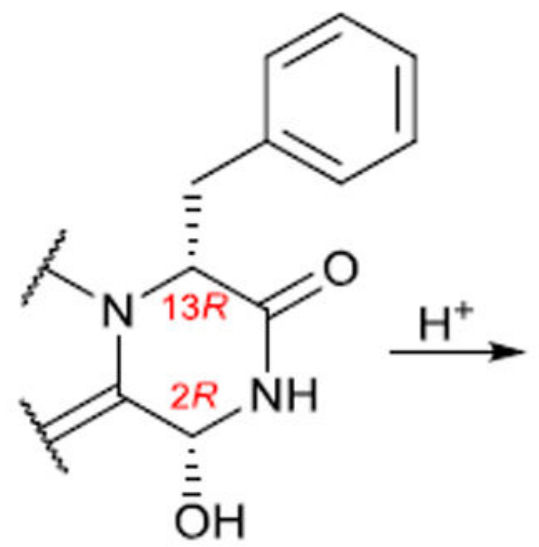

27b

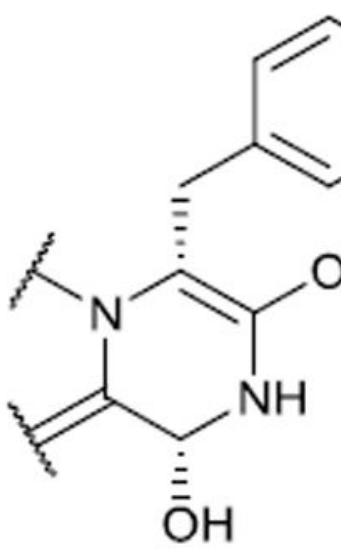

$\mathrm{OH}$

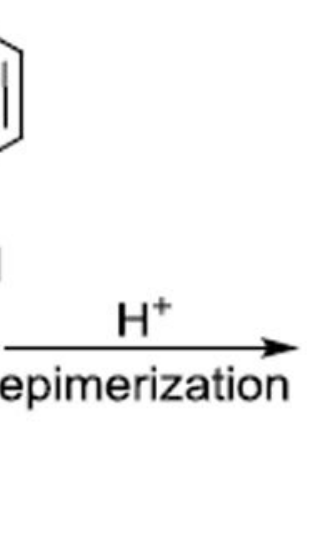

$\underset{\text { epimerization }}{\stackrel{H}{ }}$

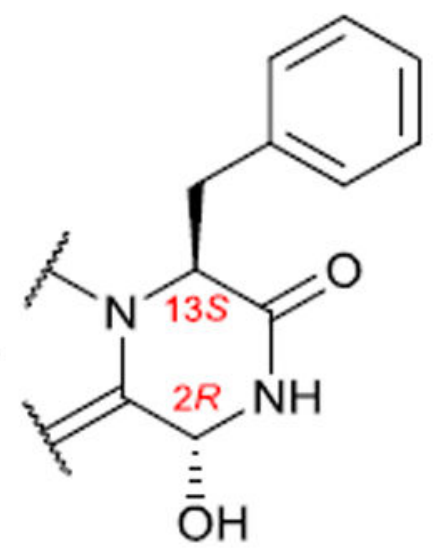

27c

Fig. 5.

Hypothetical epimerization reaction of $\mathbf{2 7} \mathbf{b}$. 


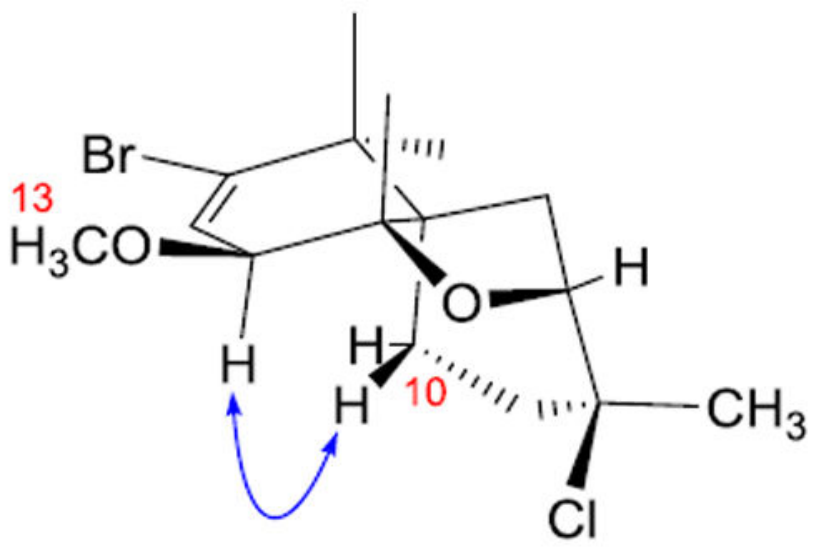

$37 a$

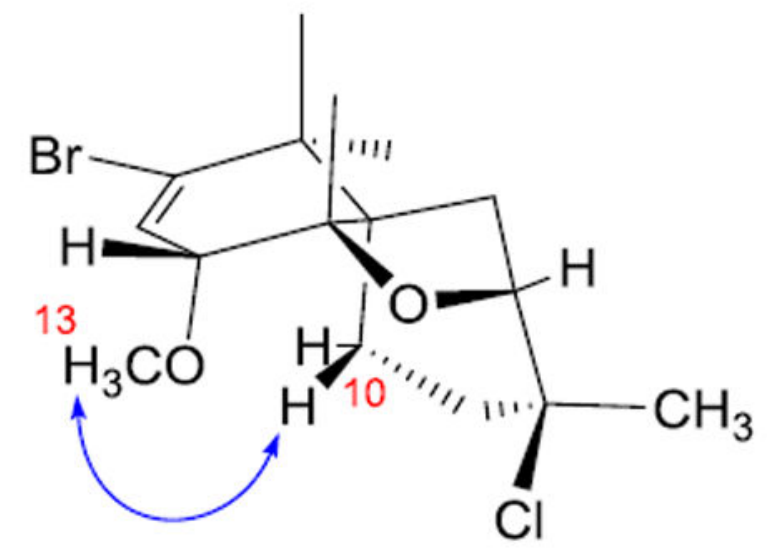

$37 b$

Fig. 6.

1D NOE NMR signal enhancement ${ }^{97}$ favoring $\mathbf{3 7 b}$ as the correct structure of cycloelatanene $\mathrm{A}$ and 37a for cycloelatanene B. 


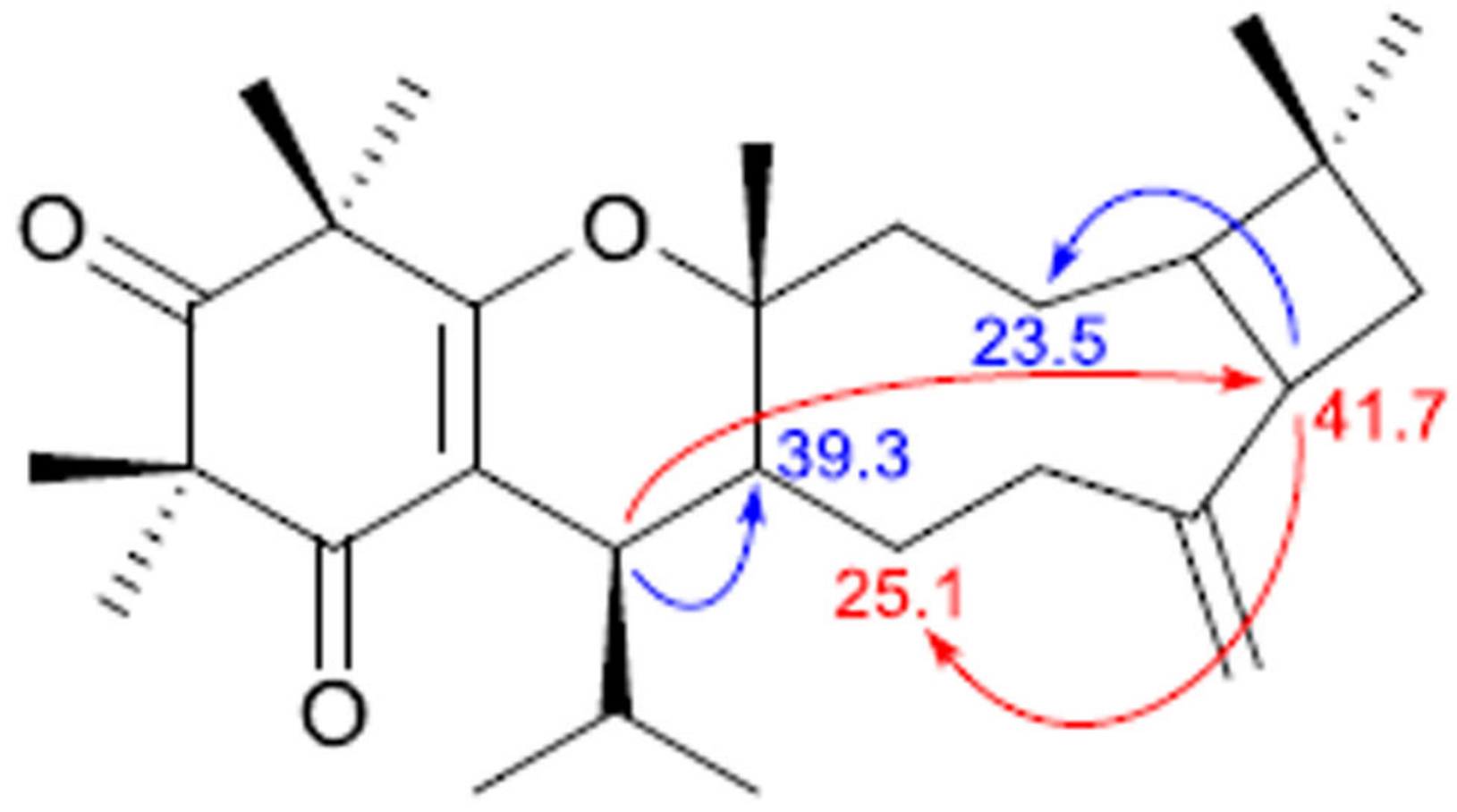

\section{$38 b$}

Fig. 7.

Improbable HMBC correlations observed in the original report (red) of 38a transposed on the revised structure and possible correlations with which they were confused (blue).

Numbers are ${ }^{13} \mathrm{C}$ chemical shifts. 
A

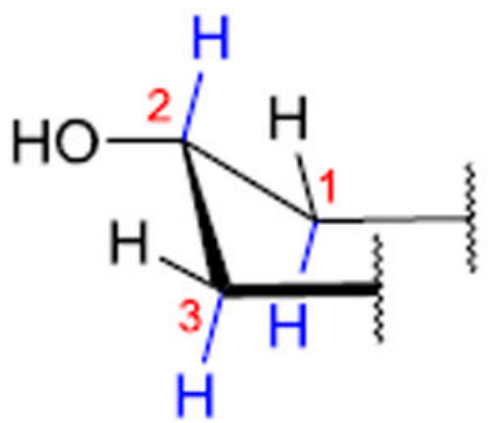

$39 a$
B

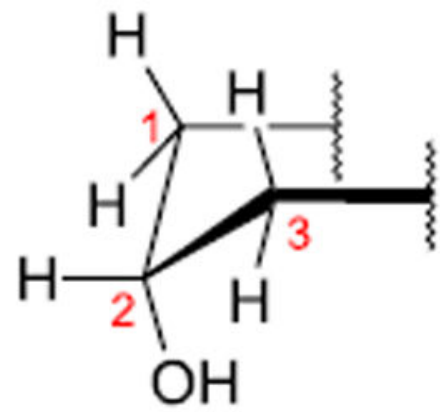

$39 a$

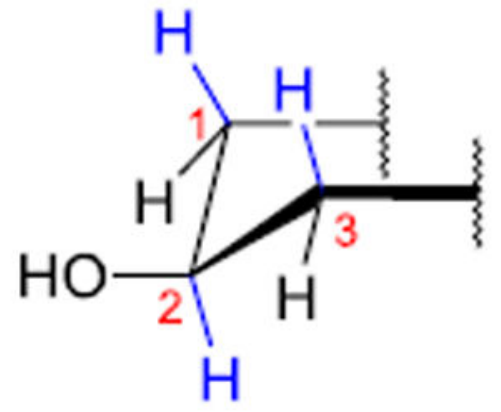

39b

Fig. 8.

(A) Chair conformation of ring A with $2 a$-hydroxy group (39a). (B) Boat conformation of ring A with $2 a-(39 a)$ and $2 \beta$ - (39b) hydroxy groups. Bonds in blue are near $180^{\circ}$ torsional angles leading to strong $J$-coupling. 
A

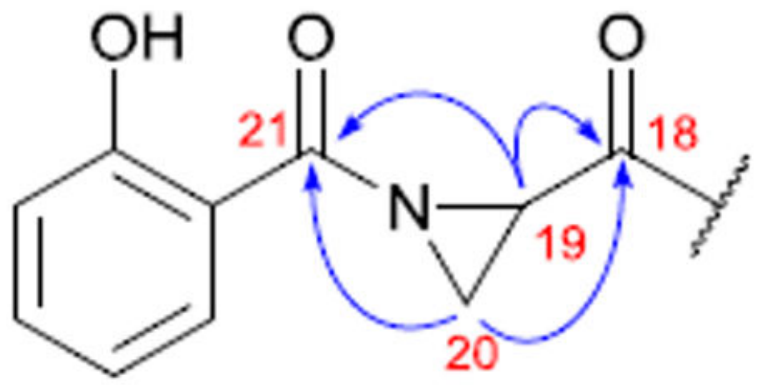

B

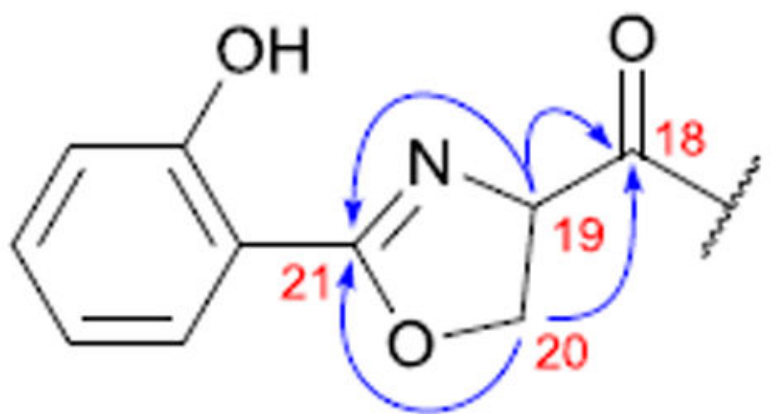

Fig. 9.

HMBC correlations for aziridine moiety present in the original proposals (A) and dihydrooxazole present in the revised structures (B). 


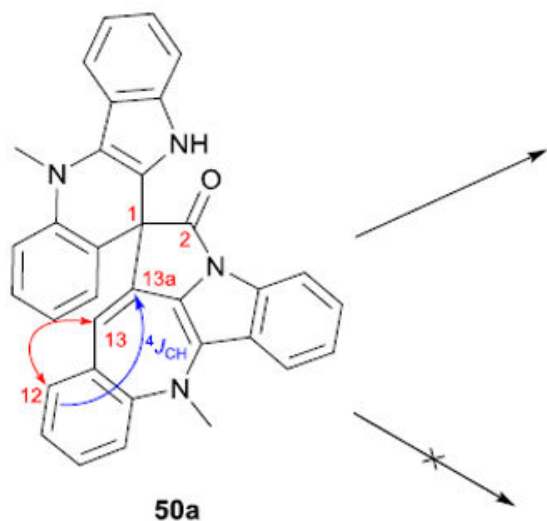

original structure
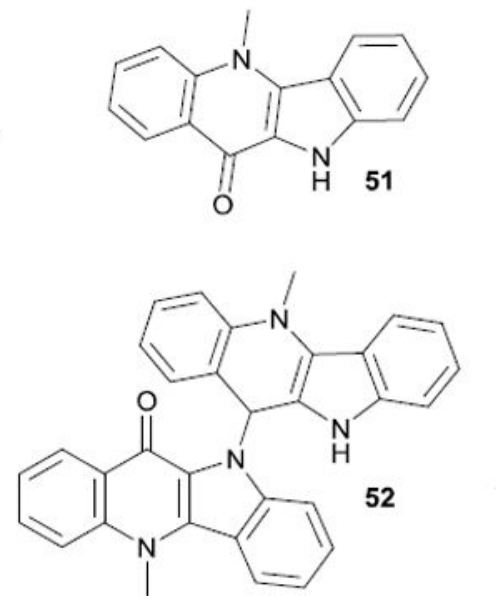

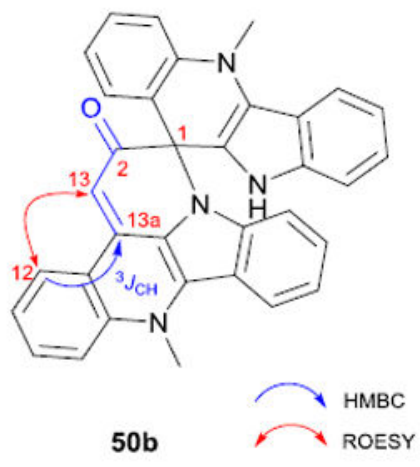

revised structure

Fig. 10.

Degradation products $\mathbf{5 1}$ and $\mathbf{5 2}$ contributed to structural revision of $\mathbf{5 0}$. 
A

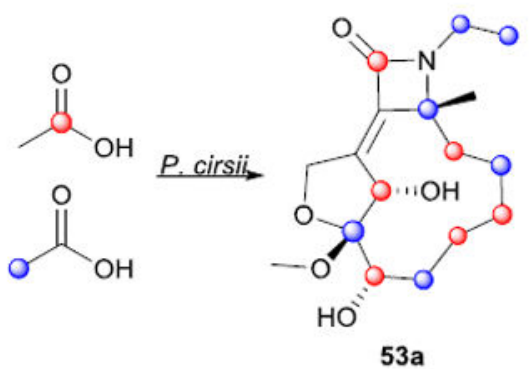<smiles>CC(=O)O</smiles><smiles>[Te]=[Te]</smiles><smiles>O=C(O)O</smiles>

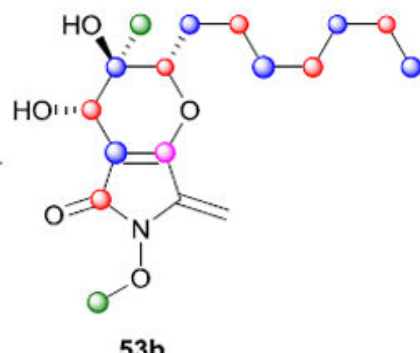

B
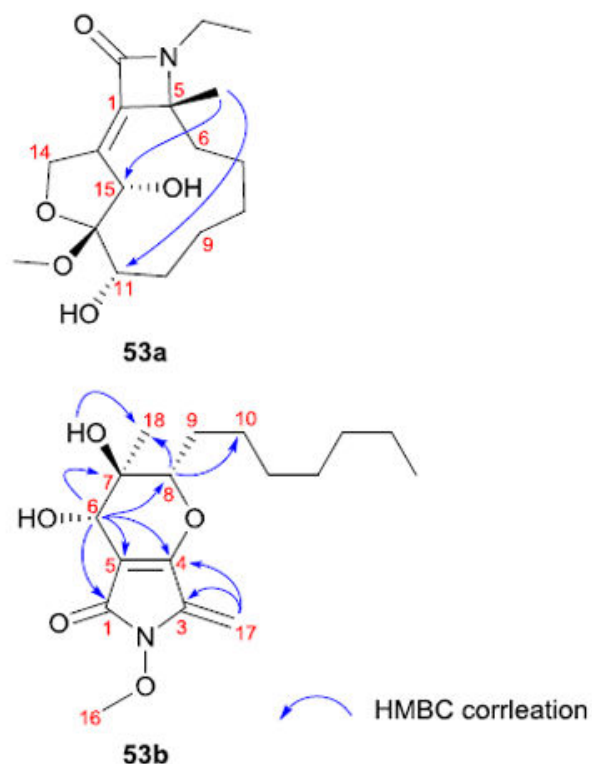

Fig. 11.

Labeled carbon distribution (A) and relevant HMBC correlations ${ }^{130}(\mathbf{B})$ projected in original (53a) and revised structure (53b) of phyllostictine A. 


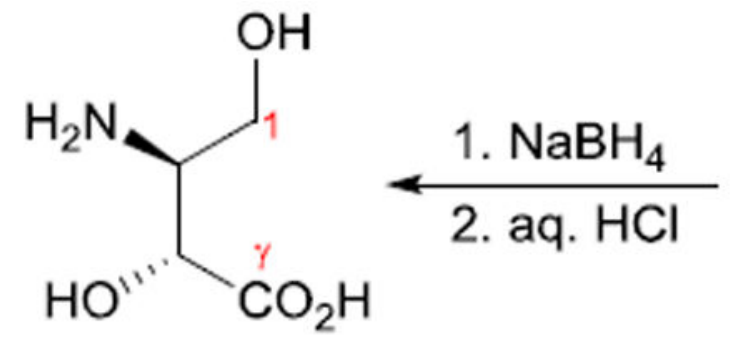

55, expected

for structure $\mathbf{5 4 a}$

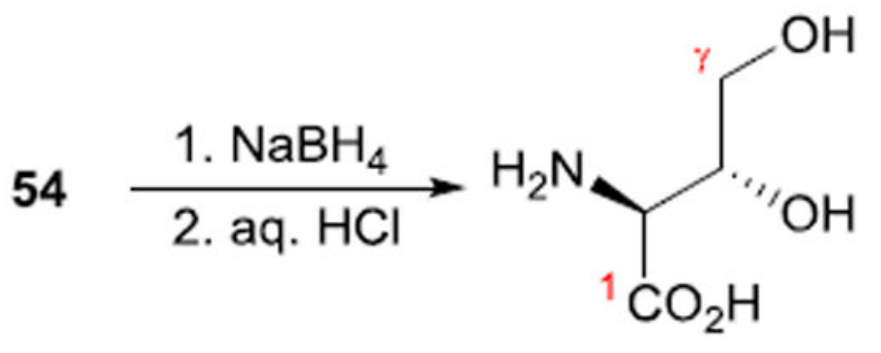

56, expected for structure 54b

Fig. 12.

Reduction and hydrolysis of poecillastrin C (54) to determine the orientation of the $\beta$ hydroxyaspartic acid moiety. 